\title{
ACUEDUCTO DE SEGOVIA
}

\section{(THE SEGOVIA AQUEDUCT)}

\author{
F. Jurado, Arquitecto \\ ESPAÑA
}

Fecha de recepción: 17-V-95

$128-64$

\section{RESUMEN}

El presente artículo plantea una visión general de la problemática metodológica y técnica que supone la intervención restauradora del Acueducto de Segovia, pieza única del Patrimonio Histórico Español. Tras una aproximación histórica al monumento, se describen los estudios e intervenciones llevadas a cabo desde el inicio, en 1992, del actual proceso restauratorio.

\section{SUMMARY}

This article offers a global vision on the issues of methodology and technique in the case restoration of the Segovia aqueduct, a unique monument in the Spanish Historical Heritage. After a brief historical overview, a description is given of the studies and restoration actions carried out since the beginning of the project in 1992 to the present day.

\section{Algunos datos descriptivos e históricos}

La toma de agua origen de la conducción se sitúa en el curso alto del río Frío. El azud o pequeña presa de derivación de las aguas, formado por piezas de granito engrapadas con llantones de hierro recibidos con plomo, puede derivar hasta un caudal de 50 litros por minuto.

Su conducción enterrada, de unos $11,4 \mathrm{~km}$, fue entubada en 1929 mediante tubería de cemento de 50 y $40 \mathrm{~cm}$ de diámetro, disponiéndose 110 arquetas que van marcando el trazado, prácticamente original.

Posee un primer castellum aquae, llamado la Casa de Piedra, construcción rectangular de 5,50 × 5,90 m de mampostería con mortero de cal, en forma de bóveda apuntada y con un depósito enterrado en su interior de $2,25 \times 3,10$ y 2 m de profundidad.

A partir de esta casa empieza el canal de granito vaciado en forma de U. Pasa bajo la actual carretera de San Ildefonso y se ha perdido un tramo que fue desmontado al variar la rasante de la carretera.

La zona elevada comienza con unos sillares cilíndricos del siglo XVII que forman un obelisco donde está grabado un pergamino sostenido por dos brazos en el que se representa el acueducto. Según Somorrostro, estos sillares se encontraron cerca de la ermita de San Matías, en el camino de la Santa Cruz y fueron colocados en este emplazamiento en 1951. 


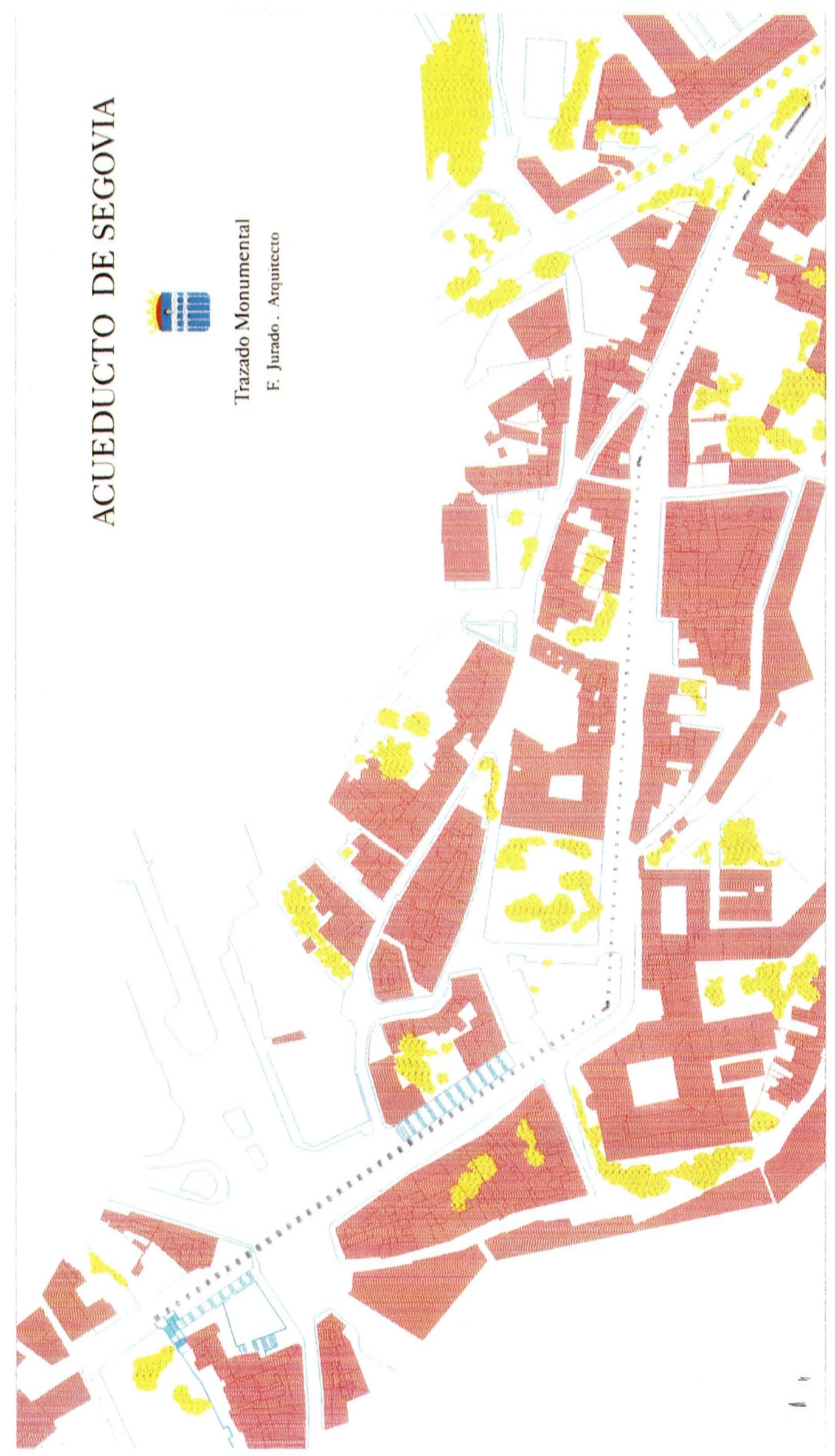


Informes de la Construcción, Vol. 47, $\mathrm{n}^{\circ}$ 437, mayo/junio 1995

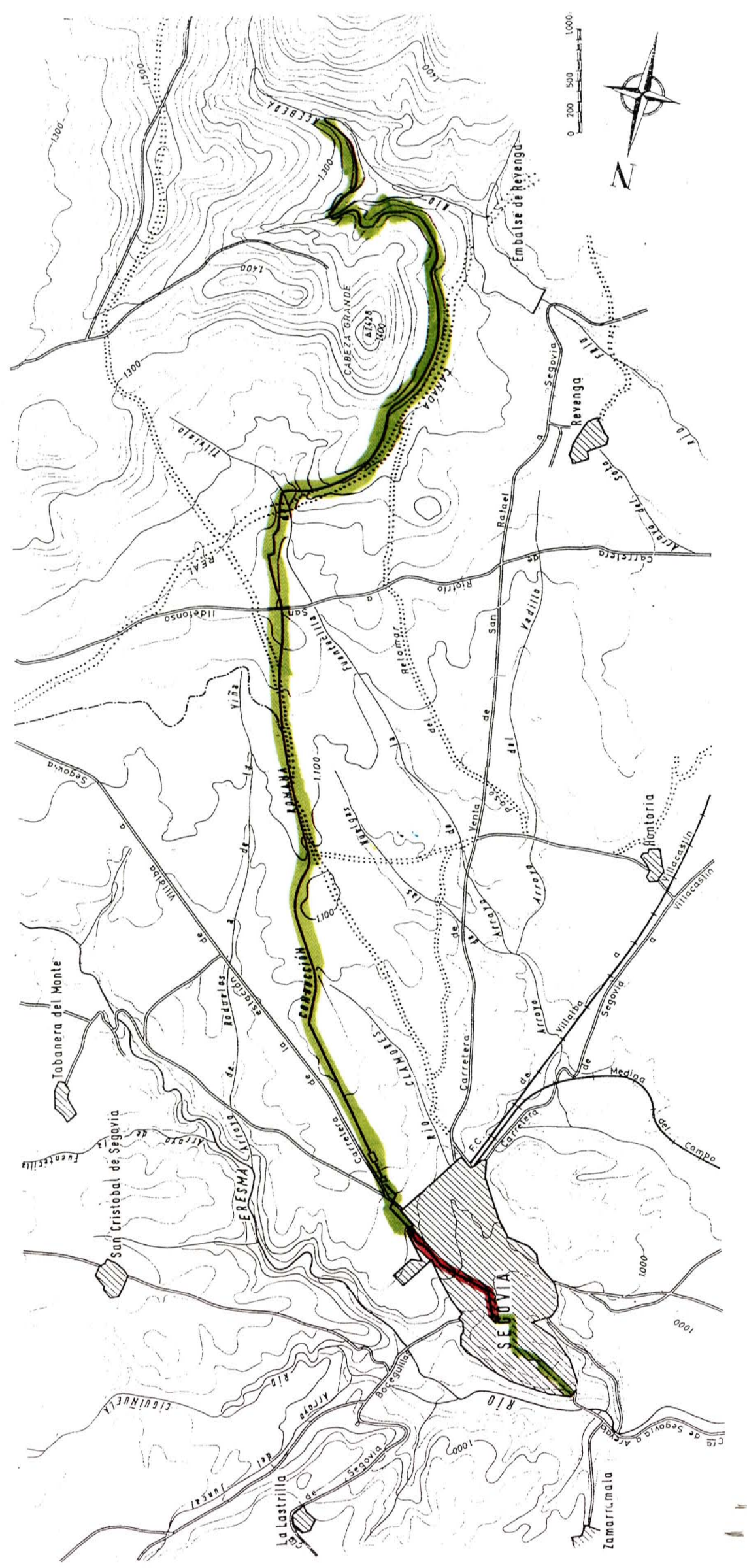

(c) Consejo Superior de Investigaciones Científicas

Licencia Creative Commons 3.0 España (by-nc)

http://informesdelaconstruccion.revistas.csic.es 


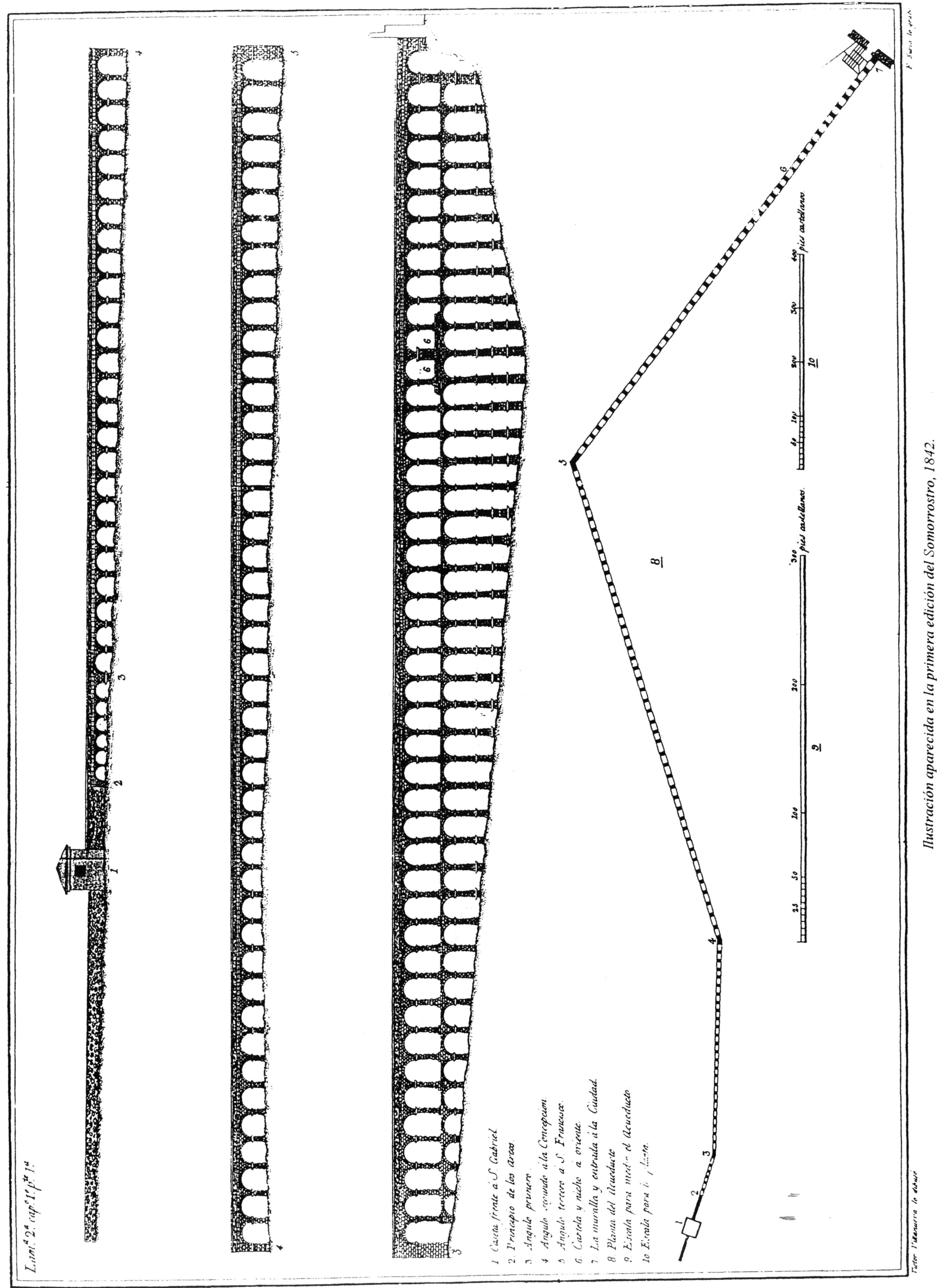




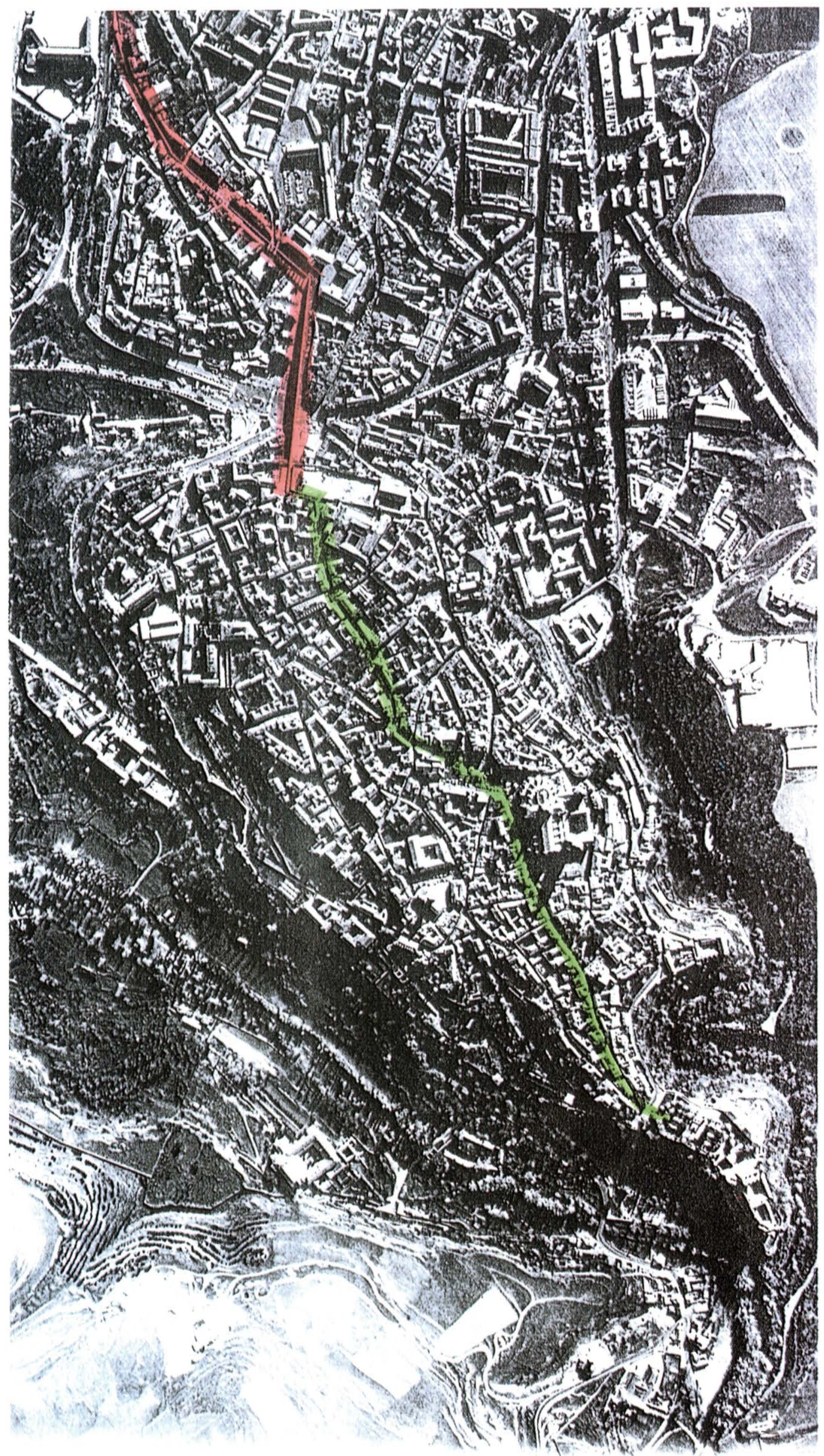




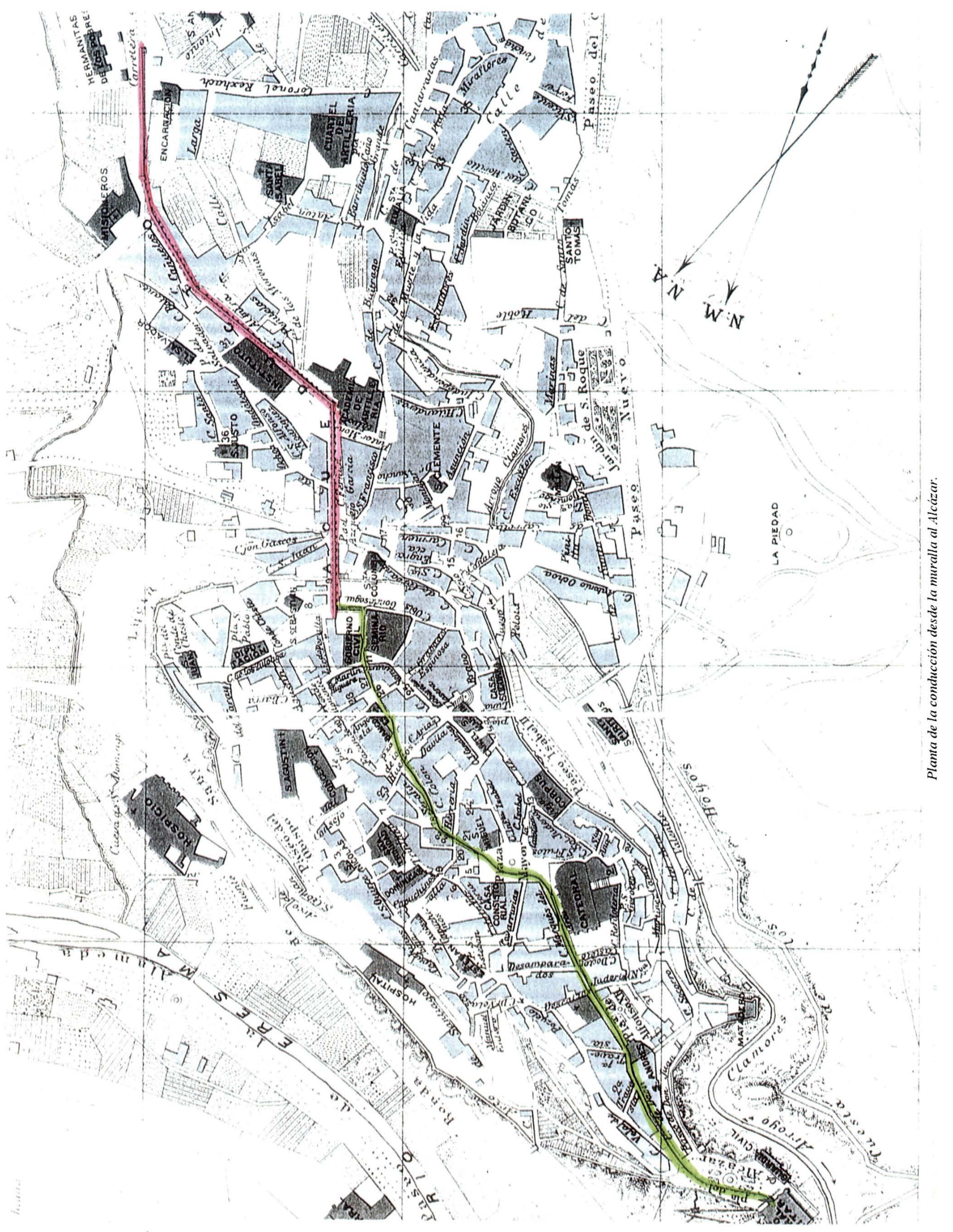




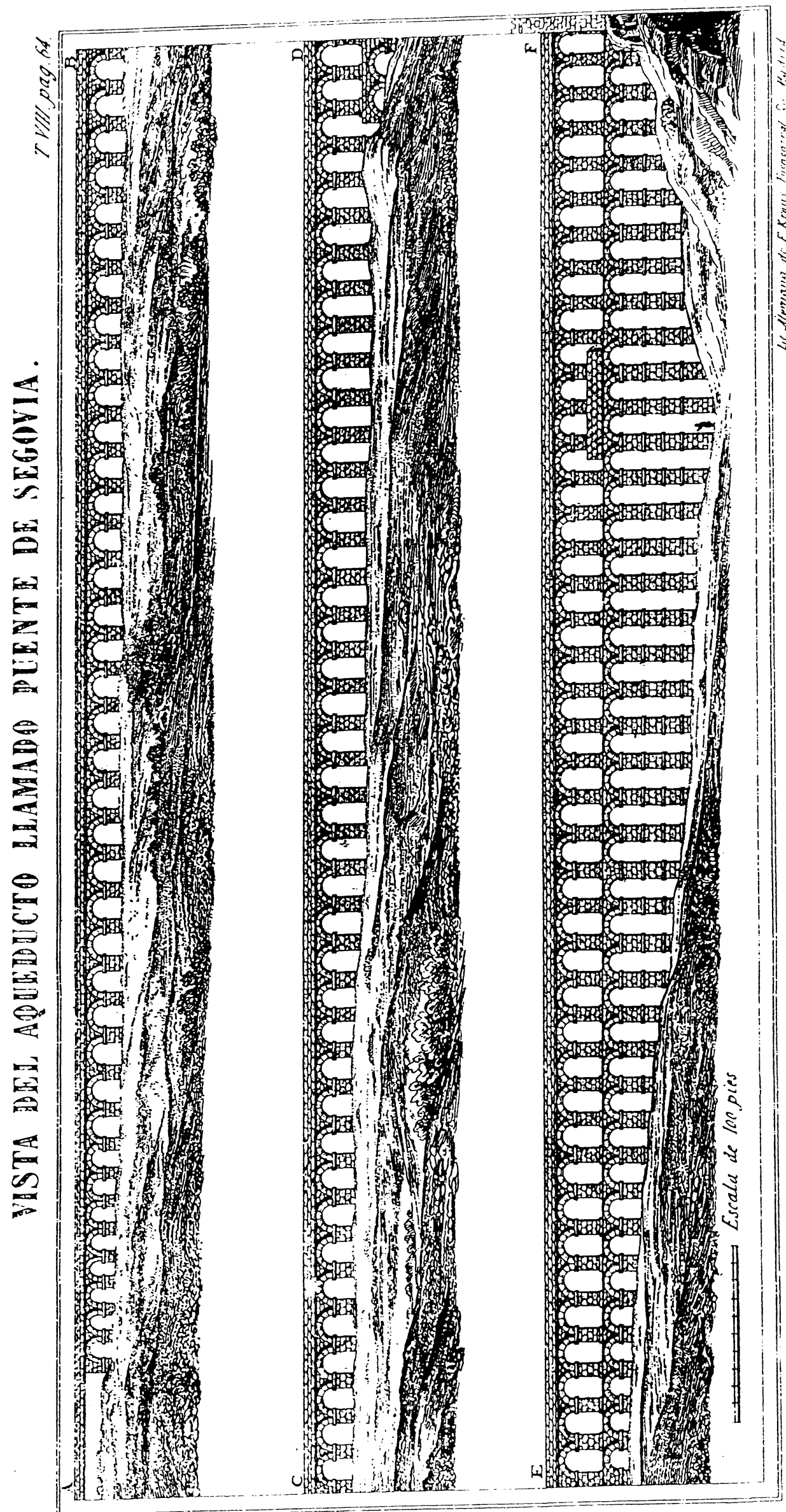


Tras 141,5 m de conducción elevada (muro de 1,4 $\mathrm{m}$ de ancho y altura desde 1,4 hasta $3,5 \mathrm{~m}$ ) se llega al segundo castellum aquae, caseta de decantación, de 8,90 x 7,50 m, con un foso en su interior de 4,25 x 2,18 y $2,90 \mathrm{~m}$ de profundidad, también cubierta con bóveda apuntada.

A partir de este punto empiezan la arquería simple y la numeración de pilas que estamos utilizando como referencia. De modo que existe una primera alineación de 6 arcos, otra de 25 arcos y una tercera de 44 arcos, hasta llegar a la pila 75 , donde se produce el cambio de alineación más brusco y se pasa a la doble arquería.
De la pila 35 a la 51 existen diversas reconstrucciones, una de ellas fechada en 1868, según la grabación existente en un sillar.

La doble arquería se compone de 43 arcos dobles que llegan a tener una altura de más de $28 \mathrm{~m}$ sobre la calzada, En las pilas 107,108 y 109 aparece una cartela (el sotabanco), donde existían inscripciones de letras (presumiblemente de bronce) engastadas con plomo en el granito. La pila 108 tiene un grueso mayor en su zona superior y tiene dos hornacinas (originales, por las huellas de la gafa de izado en su interior), donde se colocaron dos esculturas en 1520.

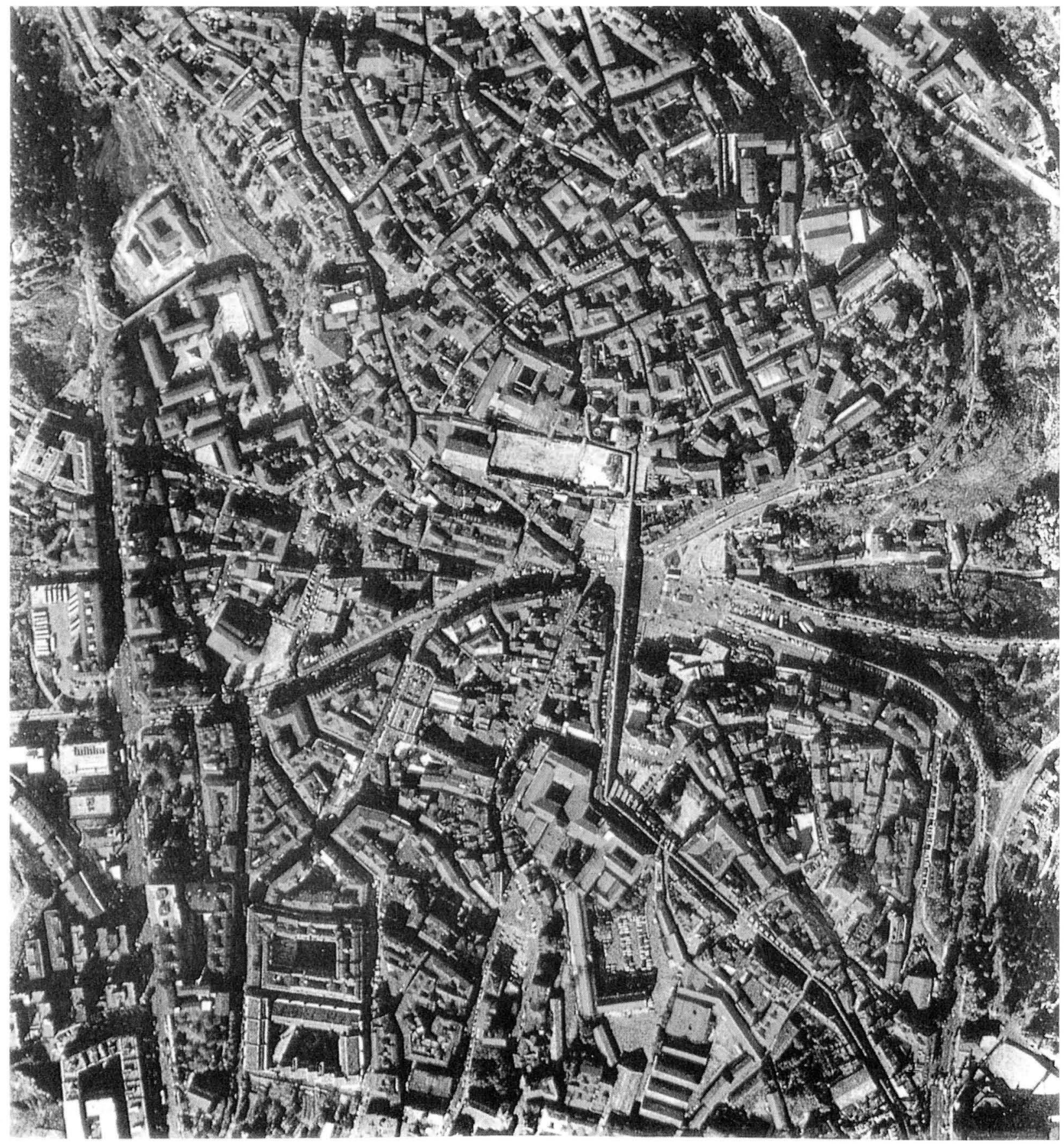

Fotografia aérea de la ciudad de Segovia, dividida en dos partes por el Acueducto. 
Atravesada la muralla (Postigo), sigue la conducción en un muro y otros tres arcos, un cambio de alineación, casi en ángulo recto y otro muro de $43,7 \mathrm{~m}$ con la conducción en su coronación. A partir de aquí, la conducción vuelve a enterrarse bajo las calles hasta llegar al Alcázar, en un recorrido de canales de piedra subterráneos de más de $1 \mathrm{~km}$, conocido en muchos tramos por las excavaciones realizadas, y habiendo servido en algunos casos para conducir aguas residuales.

En total, $15 \mathrm{~km}$ de acueducto, con $958 \mathrm{~m}$ de conducción elevada y con pendientes variables, siendo mínimas en la parte central (pilas 88 a 113), con un $0,3 \%$ de pendiente.

El canal superior actual de $30 \times 30 \mathrm{~cm}$, cerrado lateralmente con mampostería, no es el original. Éste estaba más abajo (aún existen restos con toda seguridad) y tenía una sección de unos $60 \times 60 \mathrm{~cm}$.

\section{Estudios e intervenciones que se han llevado a cabo desde 1992}

Corte del tráfico rodado bajo el Acueducto.

Medida tomada directamente por el Ayuntamiento de Segovia que, aunque genera evidentes problemas de circulación interna en Segovia, sin embargo ha sido una decisión drástica para eliminar la causa más probable del deterioro actual del Acueducto.

Realización de andamiajes y apeos para protección e inspección

Los andamios son realizados desde el 27 de julio de 1992. Han venido usándose hasta ahora para la protección e inspección

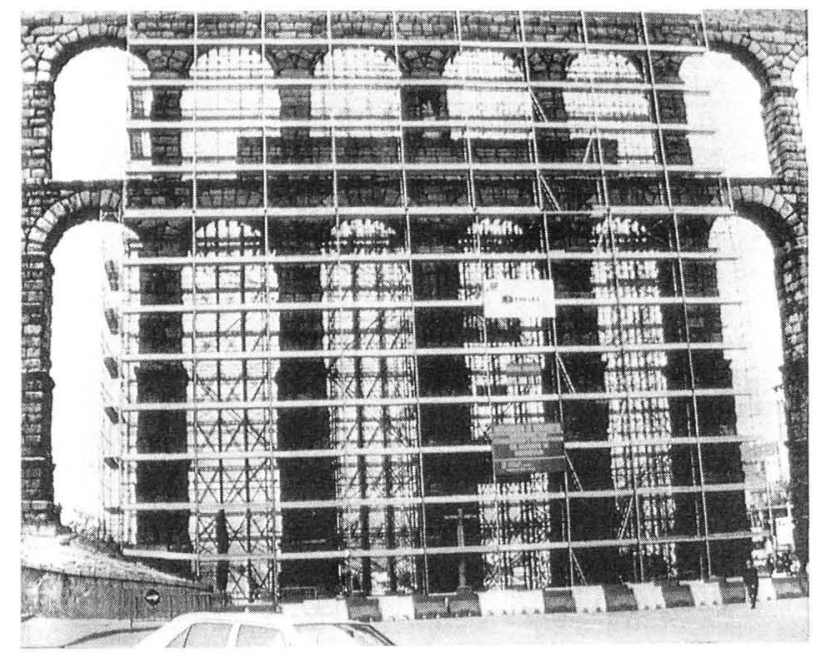

Andamiaje colocado en julio de 1992 como medida preventiva y como medio de dar accesibilidad para el estudio y la inspección detallada de la zona del sotabanco. (Fotografia proporcionada por la empresa GEOCISA).
Con fecha 4 de agosto de 1992 se inician los trabajos de colocación de apeos preventivos.

\section{Reconocimiento visual detallado}

Se ordenóla realización de unainspección visual de urgencia entre las pilas $50 \mathrm{y}$ la muralla del postigo, es decir, toda la zona de más altura, la más monumental. Dicho informe advertía de los peligros de caídas por desprendimientos de piedras, roturas locales y meteorizaciones, y otras patologias observadas en los sillares, con una clara concentración en la zona de mayor flujo de vehículos.

Se inicia el reconocimiento el 13 de agosto de 1992 y se termina en noviembre de 1992.

La inspección termina en marzo de 1993, al ser ampliado el estudio de la zona andamiada.

\section{Recopilación de la documentación existente}

Aparte de la extensa documentación bibliográfica, se ha recopilado toda la información disponible sobre las últimas intervenciones en el Acueducto. En particular hay que reseñar la obtención de interesantes fotografías (de los archivos del Ministerio de Cultura) realizadas por Laurent (1863) hace unos 115 años, o por Clifford (1853) que han servido para comparar de un modo detallado el estado que tenían los sillares entonces con el actual, apreciándose una gran aceleración del deterioro en estos últimos años.

En efecto, se puede apreciar el deterioro que ha redondeado las esquinas de las pilas, de modo que es difícil distinguir in situ el tallado de las esquinas de las mismas, como puede observarse en las fotografias de hace un siglo.

¿Cuáles son, por tanto, los factores que han aparecido en estos últimos cien años para que se deteriore la piedra más que en los dieciocho siglos anteriores? La respuesta es, evidentemente, el tráfico de los vehículos y la contaminación atmosférica.

Se destacan entonces estas dos grandes causas como las vías para investigar el origen de la actual degradación que, visualmente, ya se observaba en el Acueducto.

\section{Medición de contaminación e inmisiones}

En un primer momento, octubre de 1992 , se realizan mediante una unidad móvil, y, a partir de enero de 1993, se instala una unidadfija en coordinación con el Ayuntamiento de Segovia.

Se han realizado medidas de parámetros climatológicos y de magnitudes en función del ciclo estacional. 


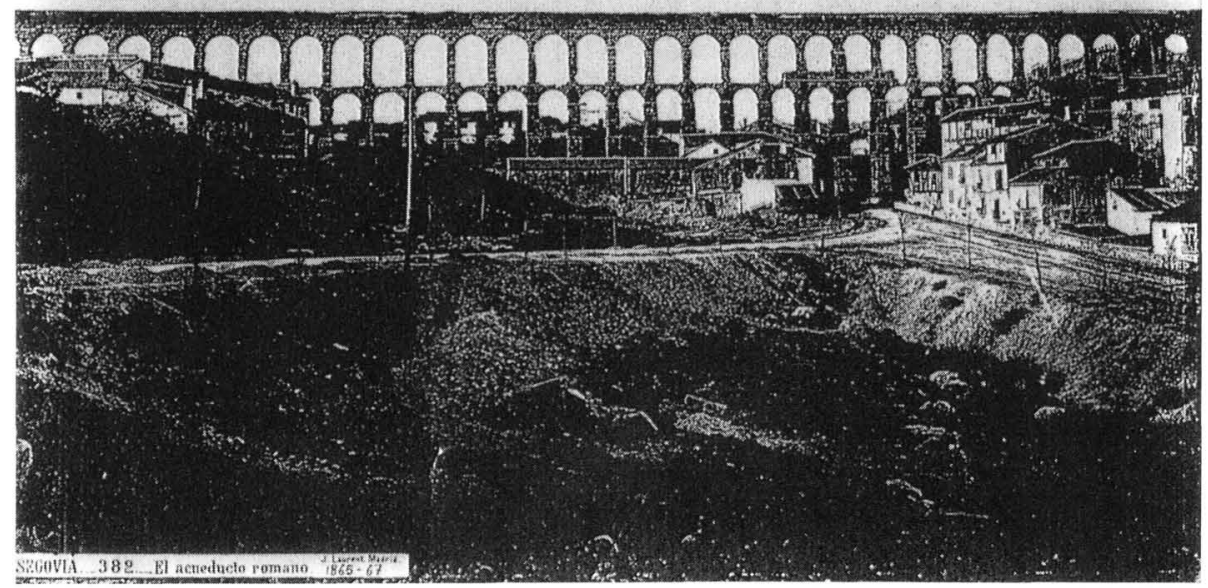

Vista del Acueducto desde la plaza Oriental en 1865-1867. Estando más arropado por las edificaciones, emergía con mayor altura por encima del caserio. La conducción entubada superior será eliminada en 1973. (Reproducción de $45 \times 25 \mathrm{~cm}$ del archivo de J. Laurent, facilitada por el Ministerio de Cultura).

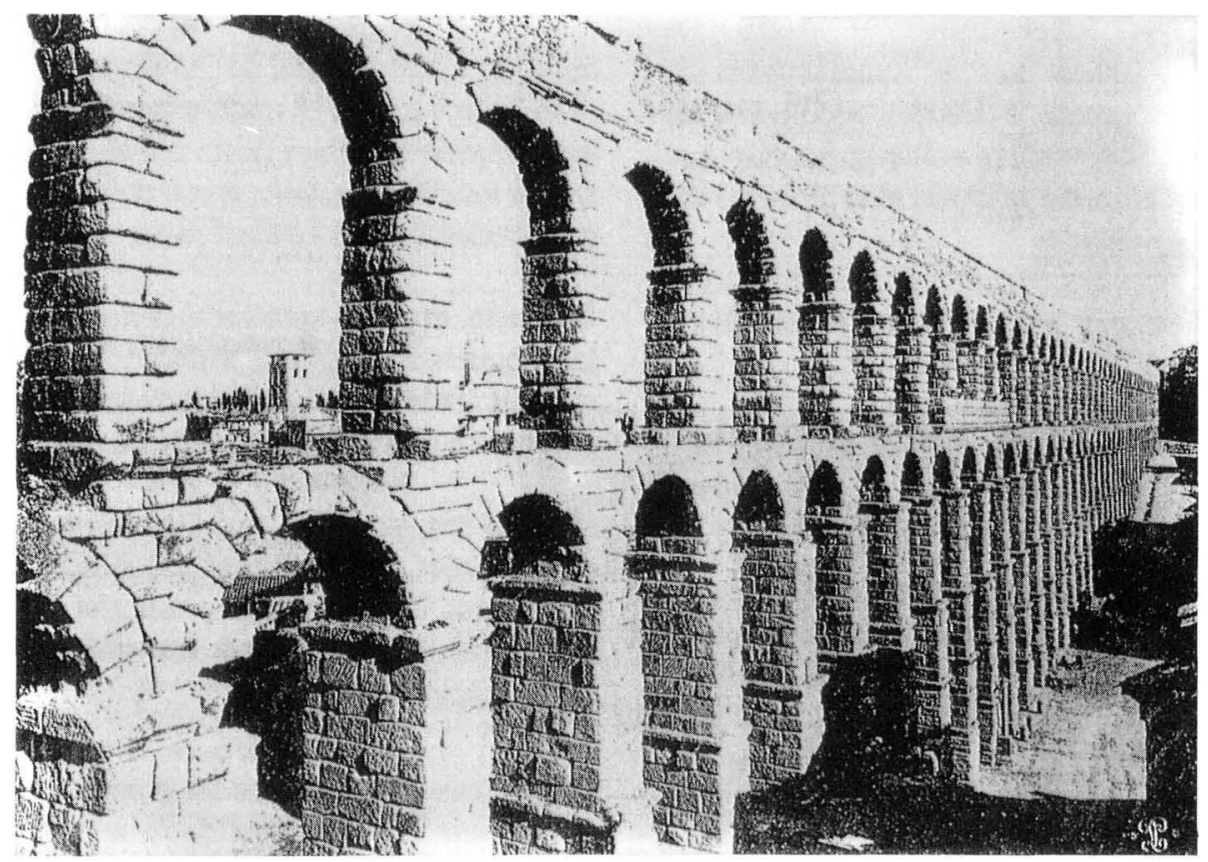

Vista del Acueducto desde la muralla en 1865-1867 (a la derecha la plaza del Azoguejo). Se puede observar un mayor detalle en las aristas de pilas y dovelas, hoy dia, 130 años después, más redondeadas. (Reproducción de $45 \times 25 \mathrm{~cm}$ del archivo de J. Laurent, facilitada por el Ministerio de Cultura).

E1 tráfico ya estaba cortado por debajo del Acueducto, por lotanto, las gráficas obtenidas corresponden a una situación bastante menos contaminada por el paso de vehículos que la que existía antes de julio de 1992, cuando se tomó esta decisión. A pesar de todo se puede observar que, en los meses de invierno, hay un claroaumento entre las emisiones de, por ejemplo, monóxido de carbono y dióxido de azufre, lo cual significa que tienen gran influencia en la contaminación las calefacciones de las viviendas.

Análisis del biodeterioro

Desde marzo a julio de 1993 se ha venido realizando, por la cátedra de Microbiología de la Universidad de Alcalá, 
estudios sobre los microorganismos que por acciones bioquímicas y biofísicas poseen capacidad para deteriorar el granito. Microorganismos que han sido aislados e identificados y que, sin duda, colaboran con otros macroorganismos: vegetales superiores y animales (pájaros, sobre todo).

Se observó un nivel anormal de microorganismos, muy alto para un granito.

Es evidente que los microorganismos del ciclo del azufre y los del ciclo del nitrógeno tienen la posibilidad de convertir
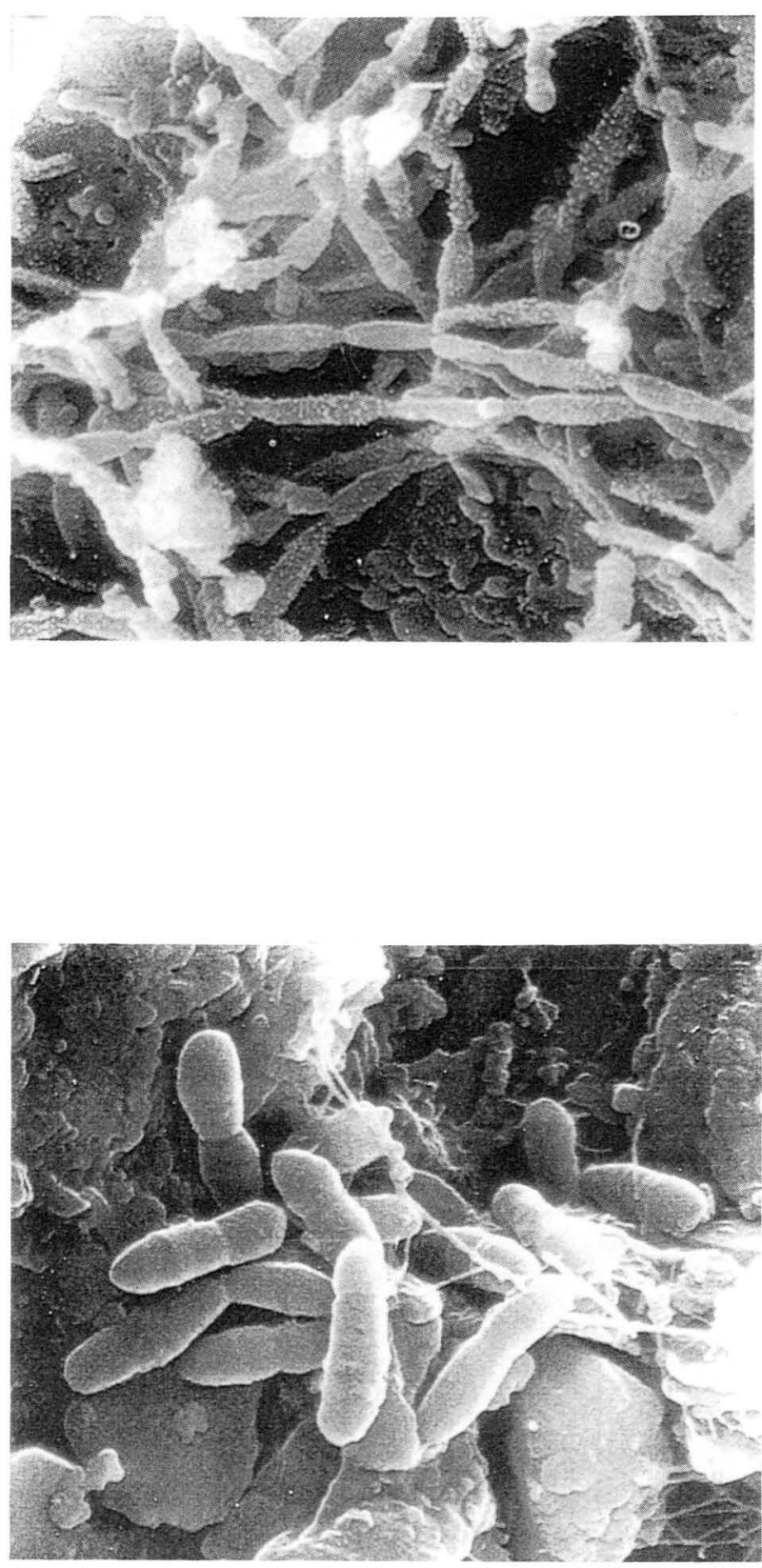

Fotografias realizadas por microscopía electrónica de barrido, en las que se observa la presencia de granito alterado, así como distintos microorganismos (bacterias, hongos filamentosos ylevaduras). (Fotografías cedidas por el profesor Fernando Laborda).

(c) Consejo Superior de Investigaciones Científicas

Licencia Creative Commons 3.0 España (by-nc) en ácidos elementos que existen en el ambiente debido a la contaminación atmosférica, atacando, por tanto, al granito.

Estudio de los materiales ajenos al Acueducto (utilizados en la restauración de 1973)

Como documentación histórica se tenía la intervención que se realizó en 1973 por los ingenieros Fernández Casado y Aurelio Ramírez, ampliamente descrita en el libro “El Acueducto de Segovia: supervivencia de una obra hidráulica" de Aurelio Ramírez, aparte de contar con la desinteresada colaboración del mismo autor.

Sin embargo, para comprobar el alcance de estas obras y el estado de conservación y/o deterioro de los materiales y productos que en ella se utilizaron, se realizó este estudio, que se terminó en marzo de 1993.

Entre otras cuestiones, se procedió a tomar muestras de los bulonados con latón y resinas transversales, así comode las zonas donde se realizaron inyecciones de lechada de cemento. También se tomaron muestras de la impermeabilización que se realizó en el canal superior.

Como consecuencia de este estudio pudimos observar que, tanto el estado de los bulones de latón, de la resina epoxídica y de la impermeabilización del canal, era de perfecta conservación. En particular, no hay ningún tipo de microfisuración en la cara del granito que está en contacto con la resina, lo que nos hace tener una "probeta" experimentada, sometida a la intemperie durante veinte años, de modo que si necesitamos volver a hacer un cosido de este tipo, podemos utilizar los mismos materiales con la garantía de su inalterabilidad.

En lo que respecta a las inyecciones verticales realizadas con lechada de cemento, afortunadamente se han encontrado pocos restos de las mismas. Decimos afortunadamente, puesto que ésta es una cuestión que debemos criticar de la intervención de 1973: el querer colmatar de un modo global las juntas entre las piedras para producir un cierto monolitismo. Muchas perforaciones estaban totalmente vacías, no sabemos si la lechada fluyó y no llegó nunca a llenarse la perforación o, con el tiempo, se ha producido tal degradación que se ha perdido totalmente.

Estamos, por tanto, de acuerdo con los bulonados transversales que se hicieron en el año 1973, puesto que lo único que se pretendía con ello era unir las piedras que se habían partido y que ejercían una labor de traba entre las dos hojas que conforman la parte superior del Acueducto, sin embargo, como ya hemos dicho, no entendemos lo de inyectar lechadade cemento para producir una aglomeración entre los sillares, cuestión ésta, ajena-a la concepción del Acueducto, piedra sobre piedra, además de los depósitos de sales que el cemento provoca al mojarse sobre la piedra, con el consiguiente deterioro. 

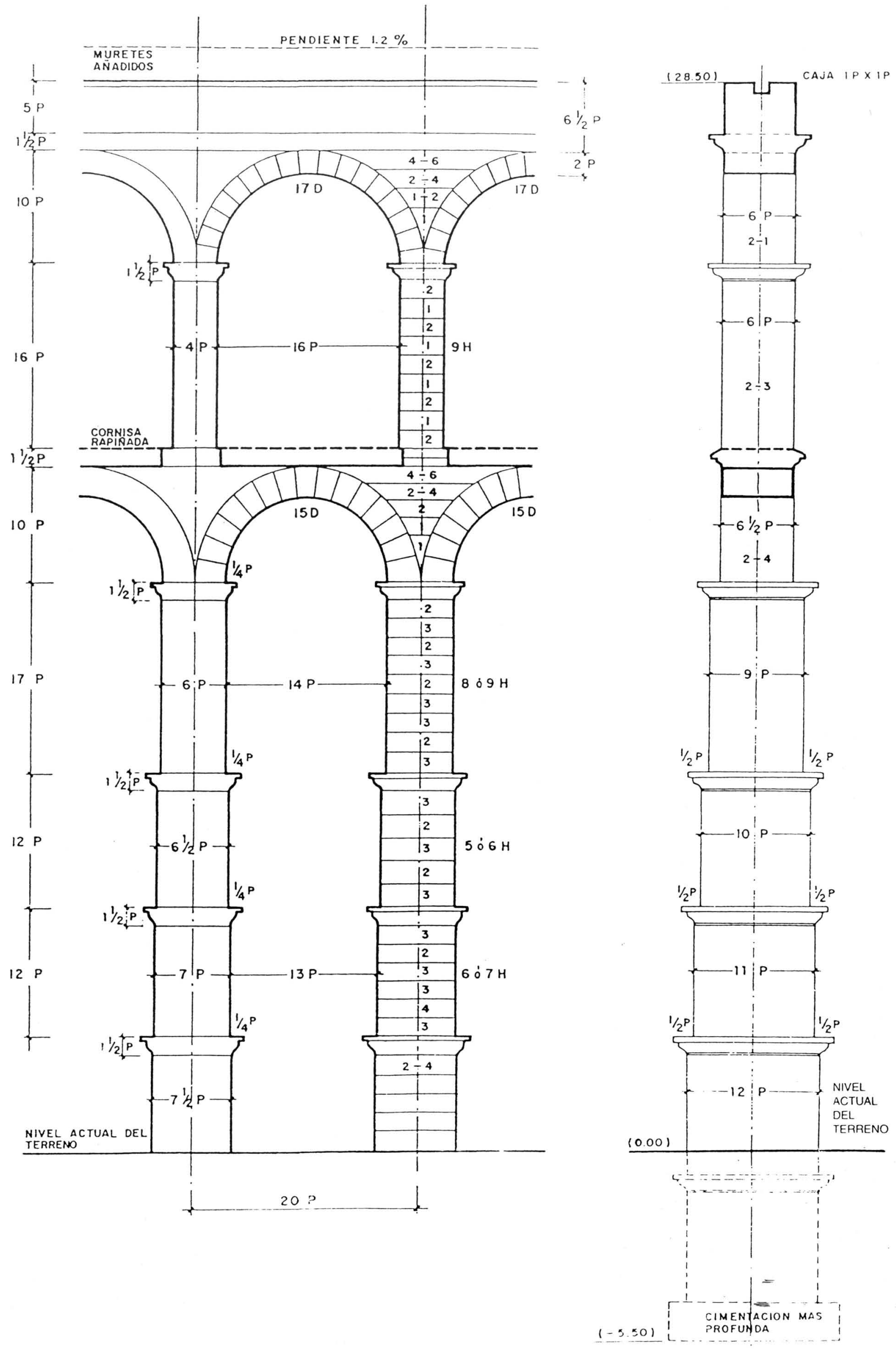

Dimensiones del Acueducto, acotadas en pies de unos $30 \mathrm{~cm}$, según el ingeniero Carlos Fernández Casado. (Ilustración extraída del libro " Acueductos Romanos en España" ). 

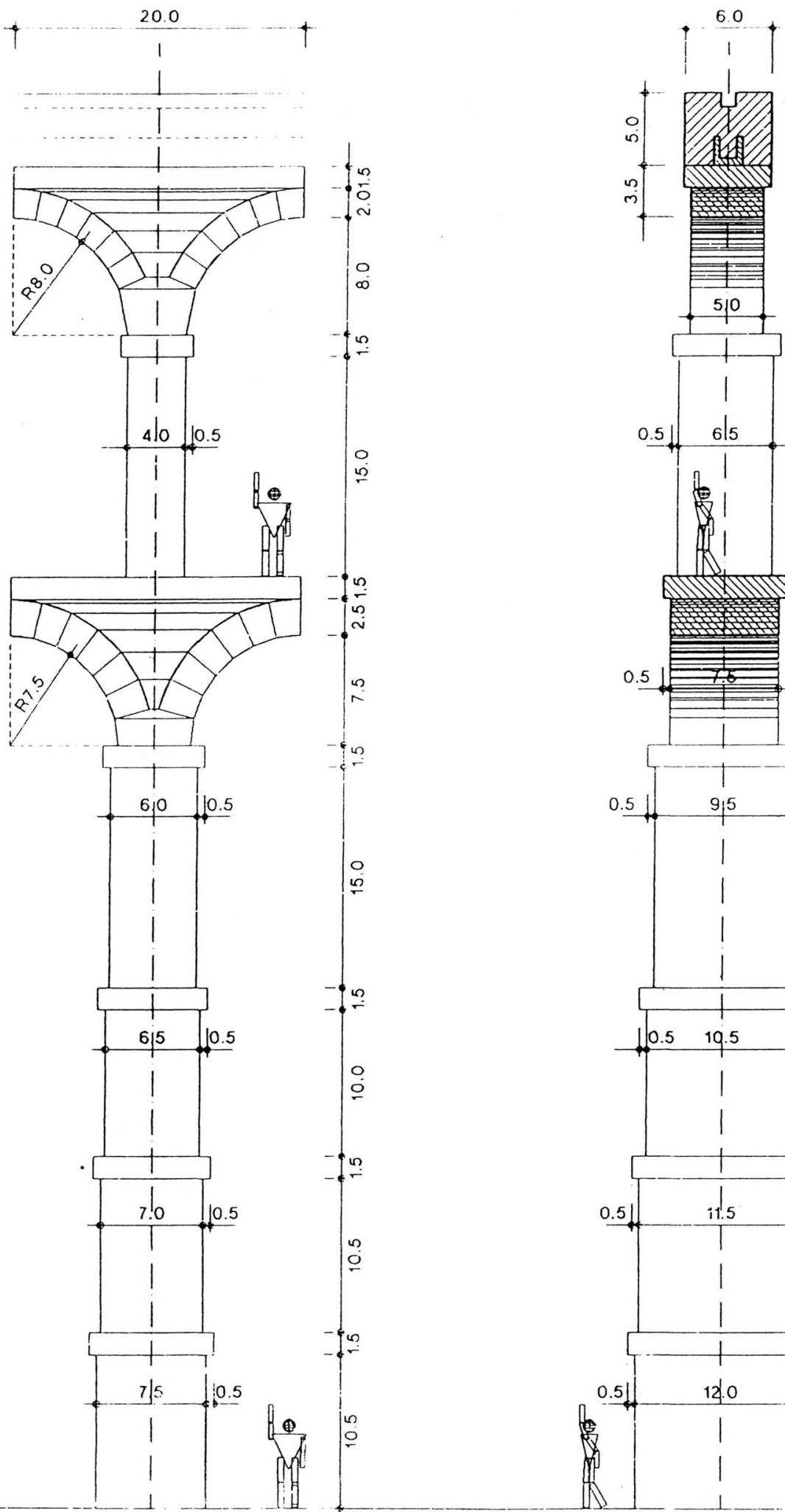

官

Proporciones reales del Acueducto de Segovia, tras haberse realizado precisas mediciones fotogramétricas. Como se puēe comprobar, los mayores errores de Fernández Casado están en las medidas transversales. sobre todo en la arcada superior. (Dibujo del autor,también acotado en pies). 


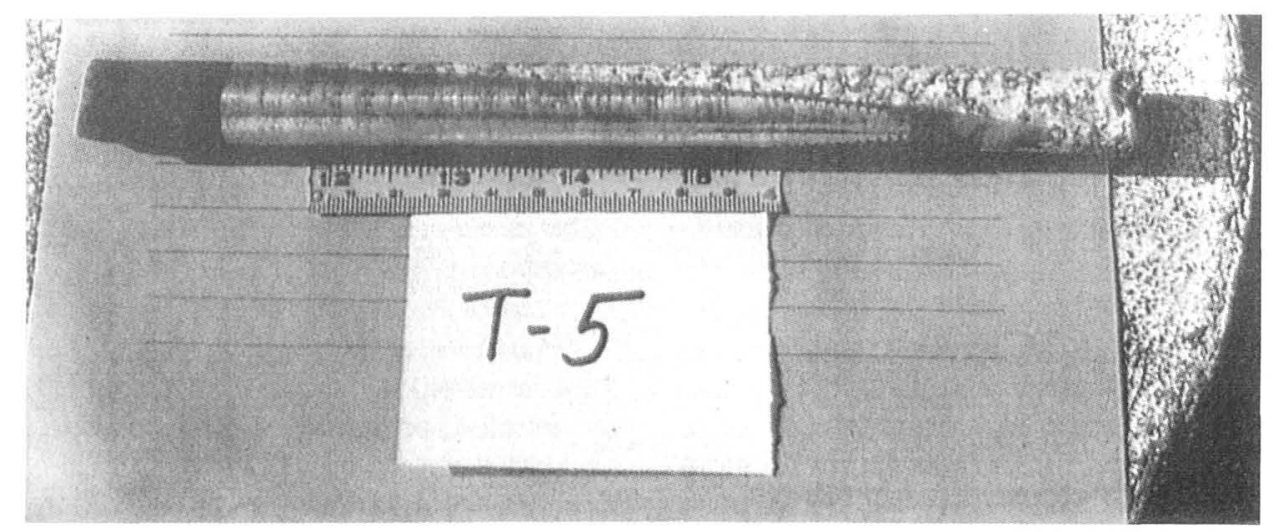

Fotografia de uno de los testigos extraidos para analizar el estado de los bulonados con latón y resina de 1973.

\section{Protecciones preventivas}

Entre enero y abril de 1993 , se colocan protecciones preventivas (mediante redes plásticas de color gris) en zonas concretas del Monumento donde pudiera haber peligro de desprendimientos, de modo que se pudieran proseguir todos los estudios hasta que los resultados de los mismos nos indicaran las soluciones a tomar.

\section{Levantamientos gráficos y fotogrametrias iniciales}

En julio de 1992 se comenzó un levantamiento fotogramétrico de la zona andamiada que no resultó totalmente satisfactorio, debido probablemente al corto plazo de tiempo de que se dispuso antes de colocar dicho andamiaje.

Sin embargo, hemos realizado una planimetría completa del Acueducto utilizando fotogrametrías parciales anteriores, planos de la ciudad de Segovia y mediciones propias.

Fotogrametria tridimensional en CAD y base de datos gráfica

Ante la evidente necesidad de poseer una fotogrametría detallada de la totalidad del acueducto, se ha encargado a finales de 1993 al equipo Latorre \& Cámara la realización de los trabajos de campo y la posterior restitución de una fotogrametría tridimensional ordenada de la totalidad del Acueducto.

Esta actuación es de suma importancia, ya que en ella se definirán de manera biunívoca todos y cada uno de los sillares que forman el monumentos, sirviendo de entrada gráfica (y también de salida) para las bases de datos que se están realizando sobre patologías, análisis, etc...

\section{Estudios sobre la piedra granítica del Acueducto}

Siendo éste uno de los aspectos de mayor importancia, desde finales de 1992 se han venido realizando

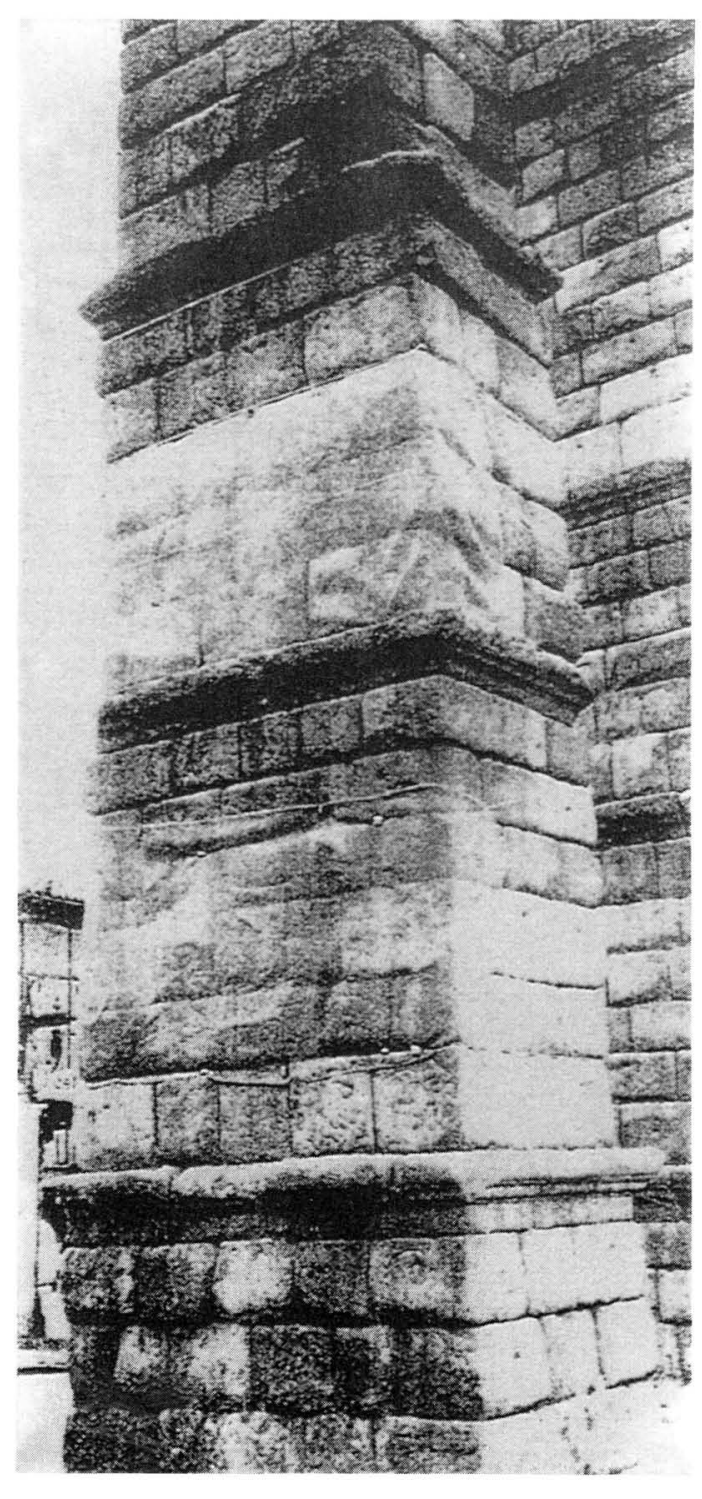

Se han colocado redes de color gris parầ evitar peligros de desprendimientos de trozos de granito en los sillares más criticos, hasta que se intervenga en ellos. (Fotografia cedida por GEOCISA). 


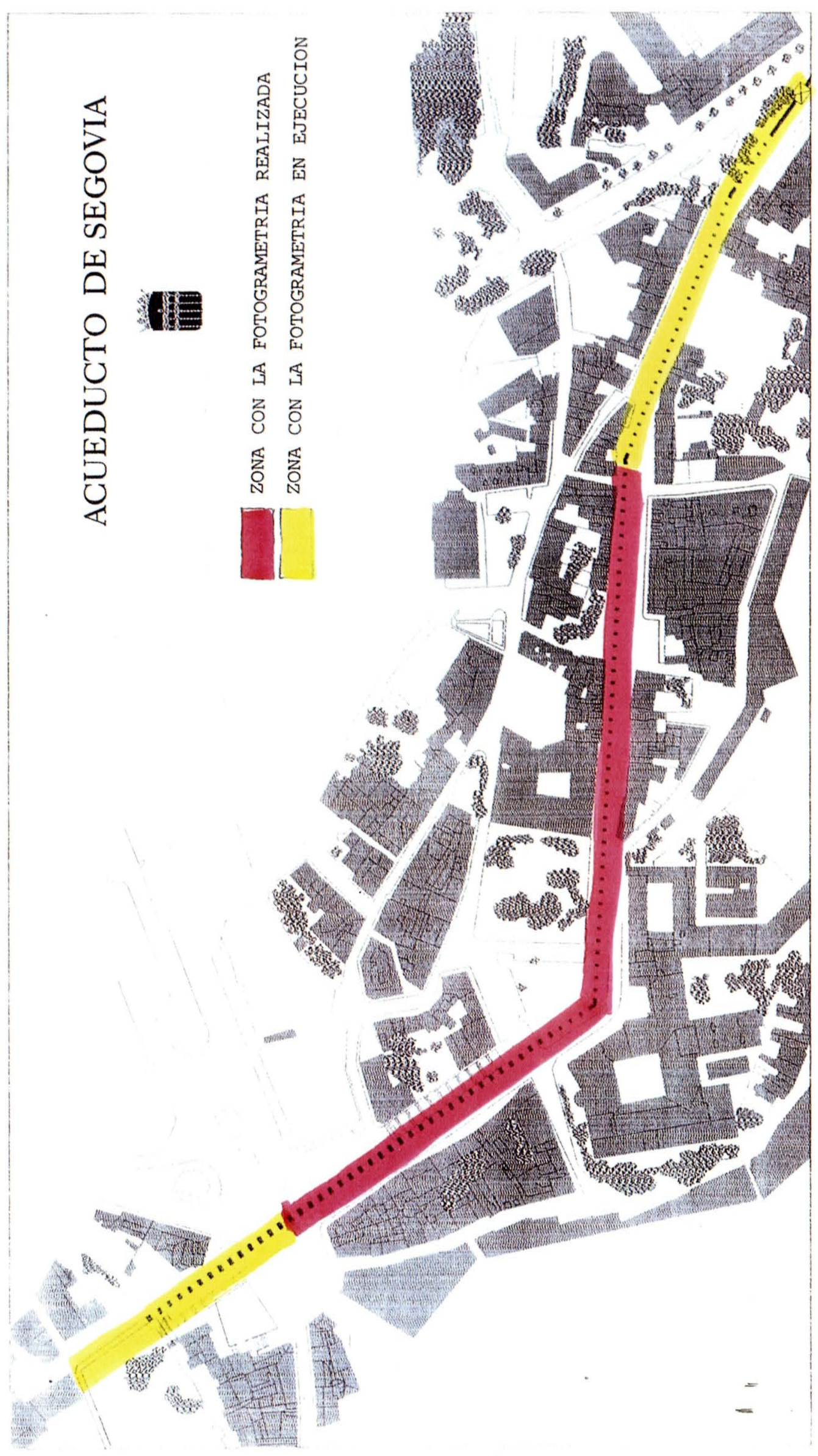




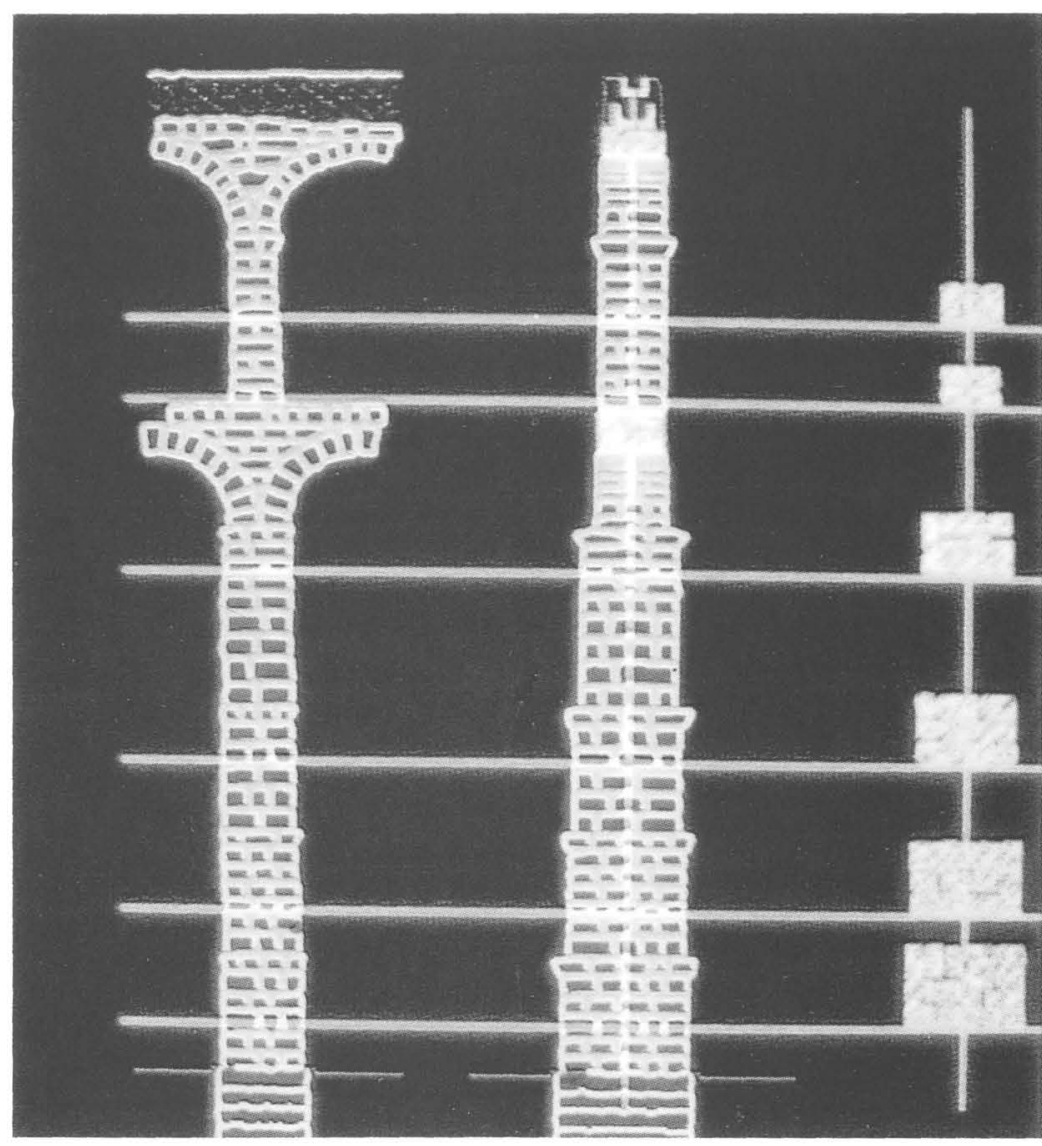

Alzados y secciones de distintas partes de una pila del Acueducto, con despieces de sillares visibles y no visibles. (Dibujos del autor antes de iniciarse la fotogrametría)

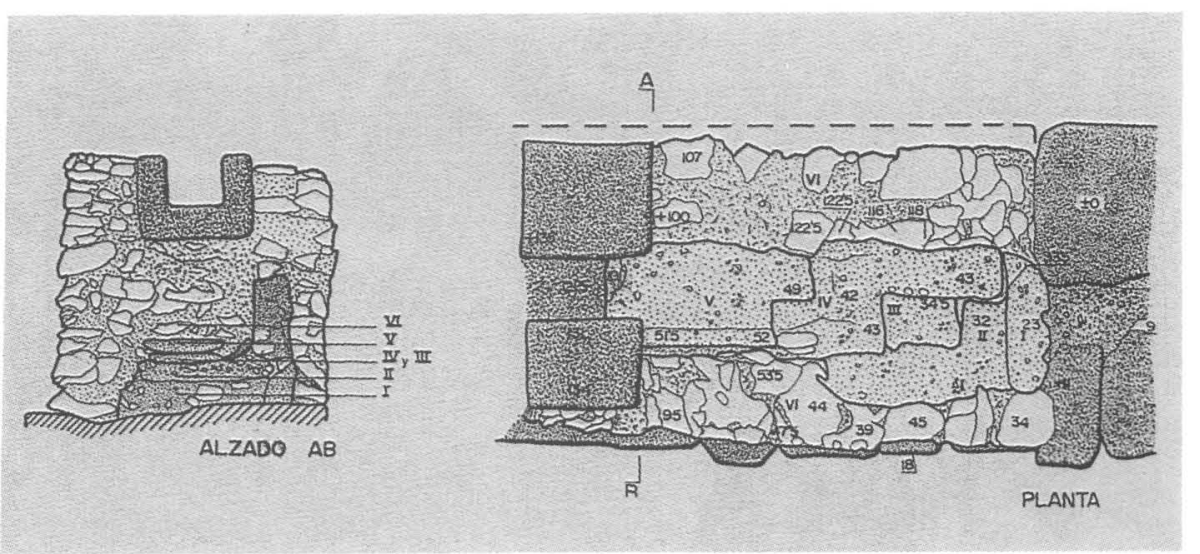

Plano arqueológico de las catas efectuadas en 1973 sobre el canal, donde se aprecia una canal inferior de mayor sección. (Dibujo cedido por el arqueólogo Luis Caballero). 


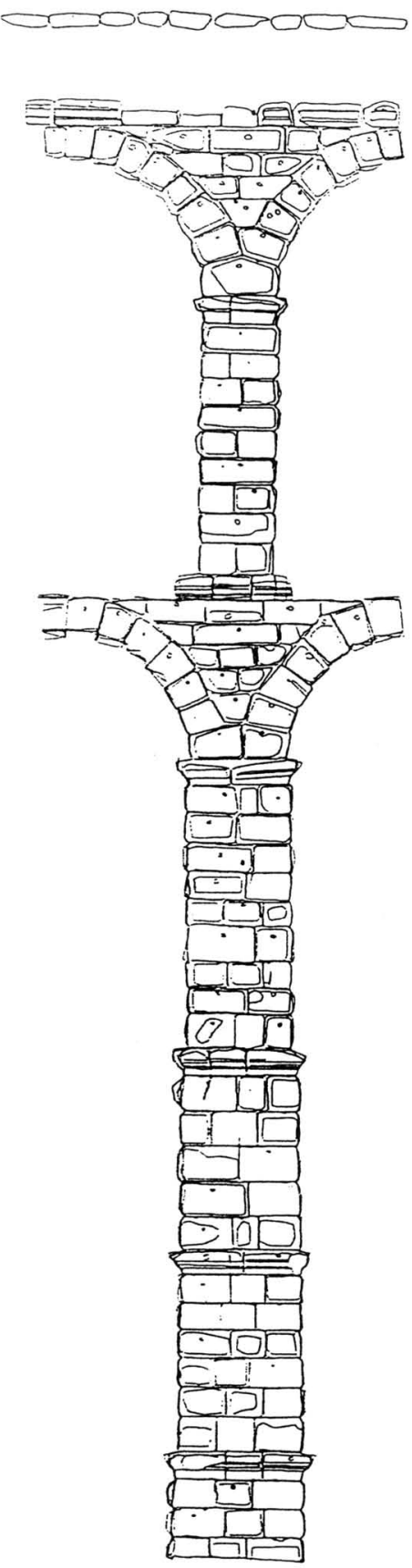

ALZADO 1

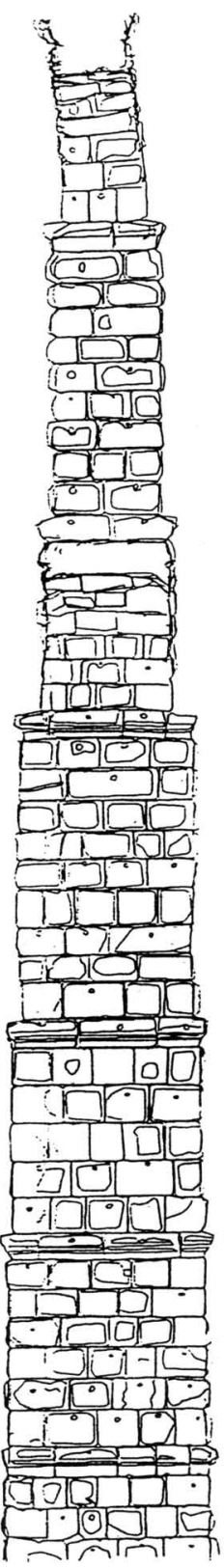

ALZADO 2

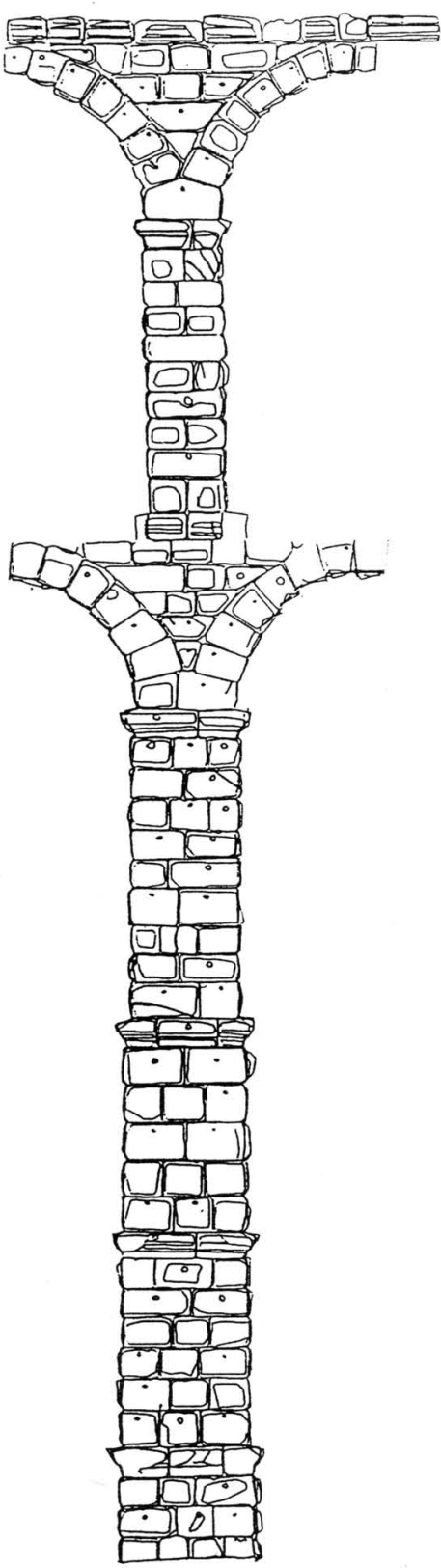

ALZADO 3
PILA n 100
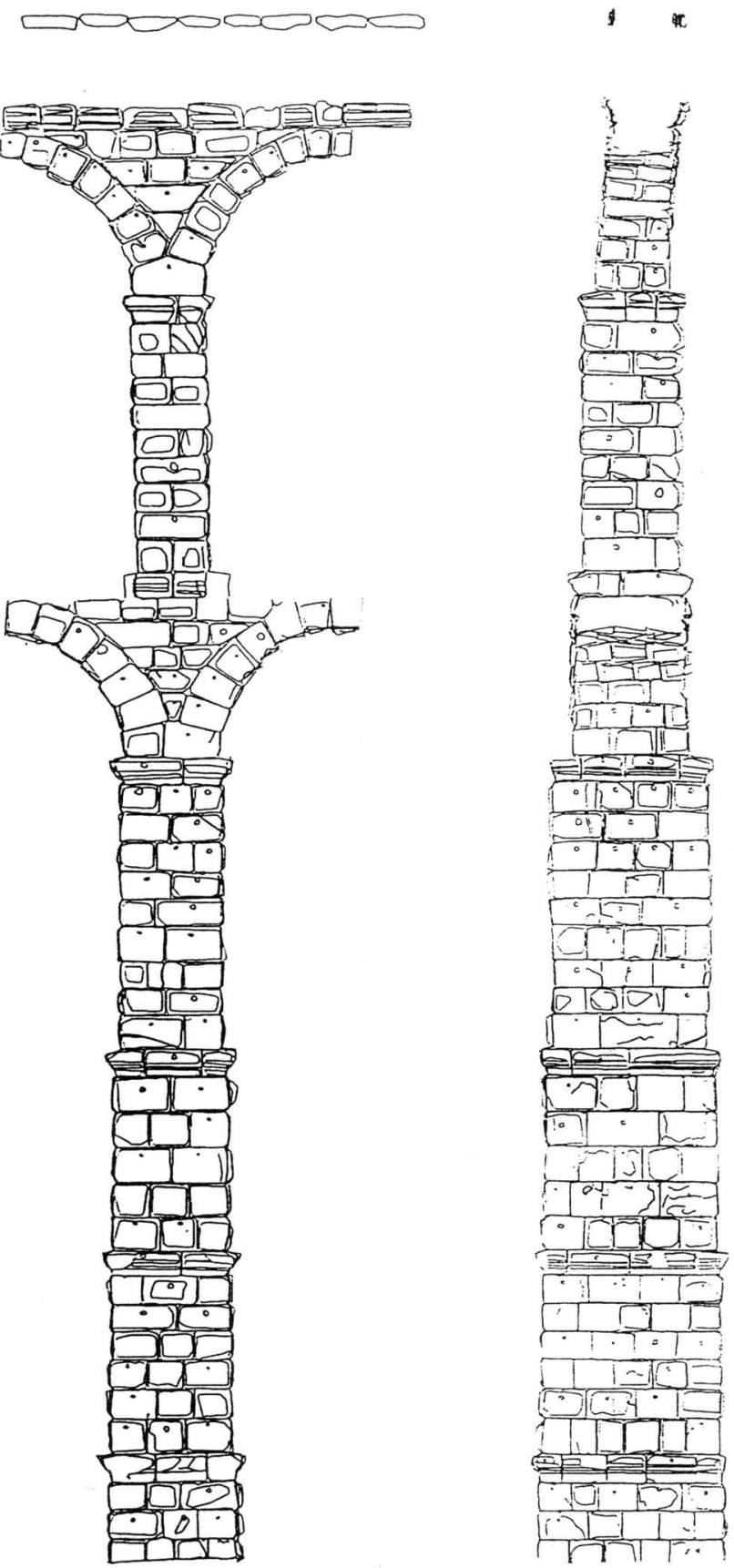

ALZADO 4

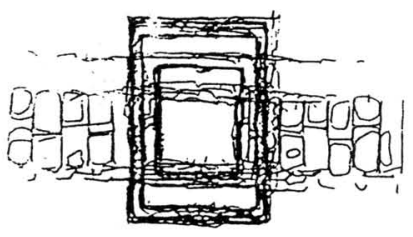

PLANTA ARCO SUPERIOR

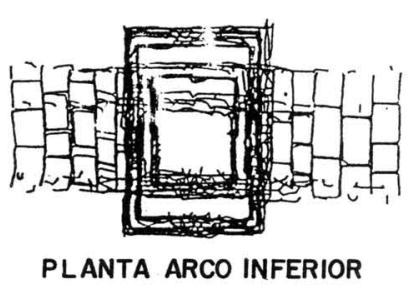

PLANTA ARCO INFERIOR

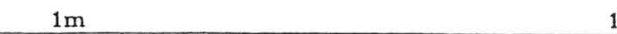
10 


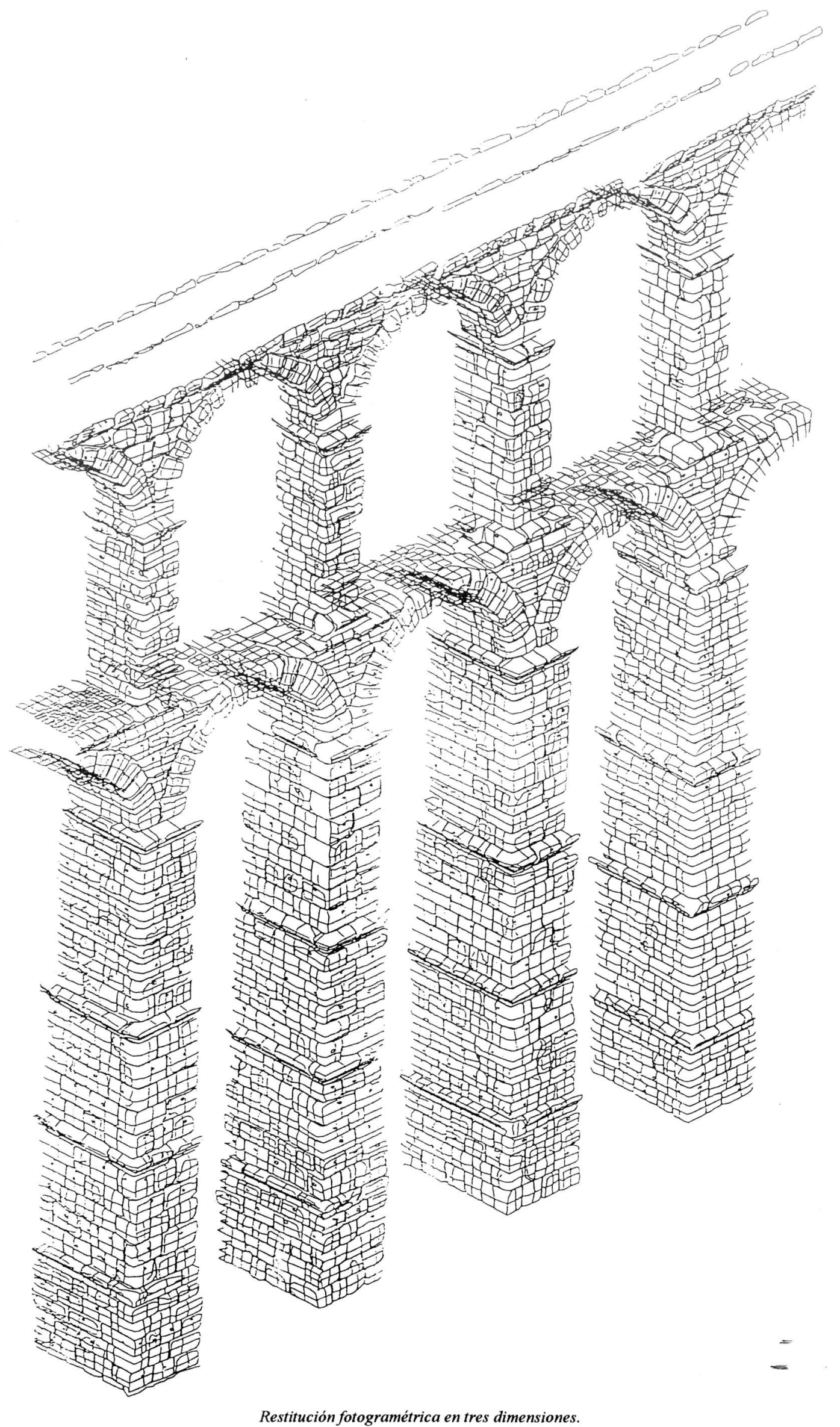

(c) Consejo Superior de Investigaciones Científicas 

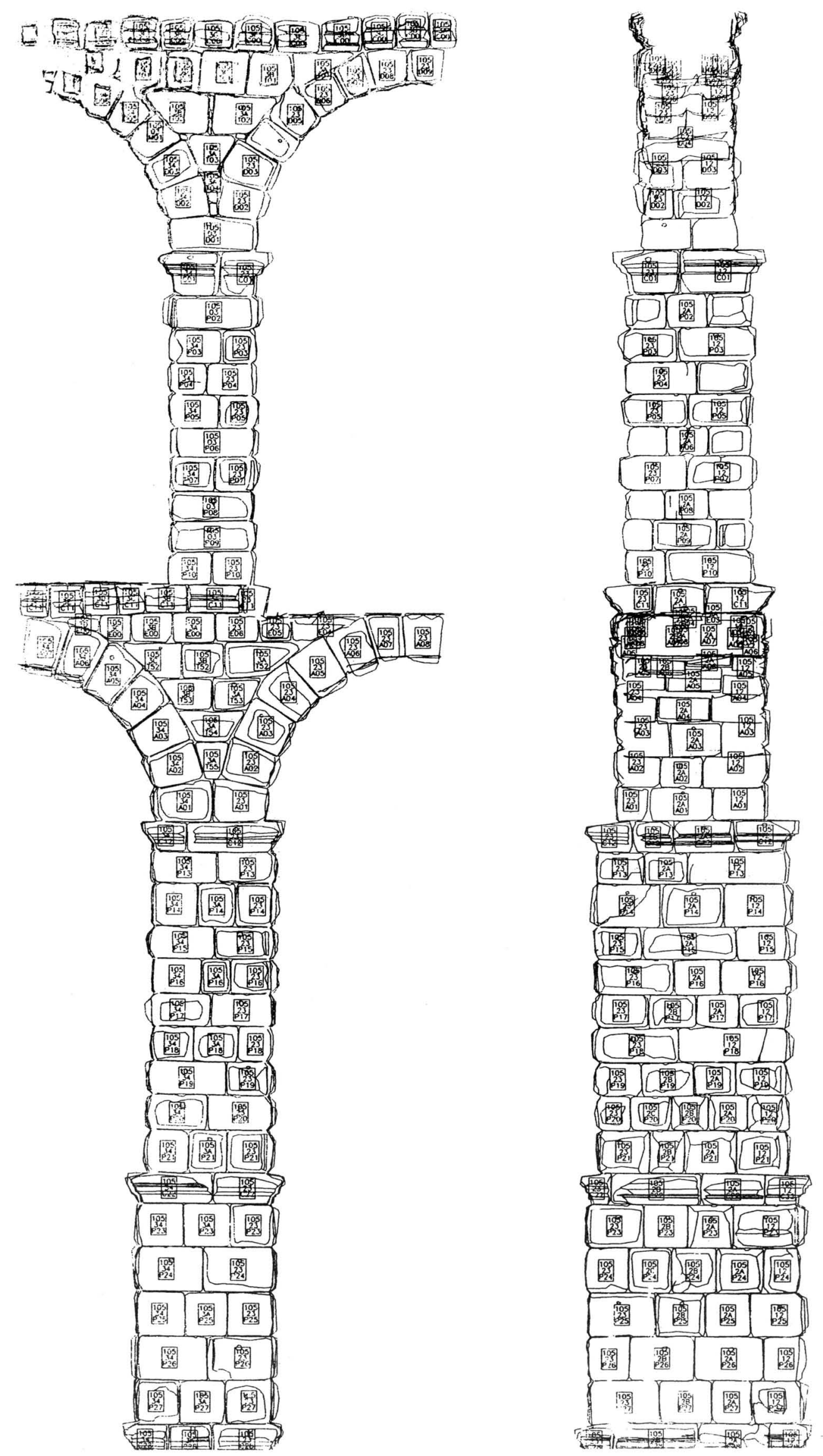

La fotogrametria tridimensional está asociada a una base de datos en la que cada sillar (identificado biunívocamente con ocho digitos) tiene su propia ficha donde se anotan ensayos, intervenciones, estado en cada época,... 
reconocimientos, toma de muestras, mediciones mediante ultrasonidos, ensayos fisico-químicos, etc.

Todo ello se recoge en el trabajo (septiembre de 1993) que determina las causas y tipo de alteraciones del granito del Acueducto.

Se procedió a tomar veintidós muestras de los sillares del Acueducto, las mínimas imprescindibles, y otras serie de muestras de tolmeras y canteras de granito similar al del Acueducto. La mayoría del granito que existe en el Acueducto es grano grueso, el granito de menor calidad.

La comparación entre el granito existente en el Acueducto con el similar extraído de canteras, depara que el primero tiene una resistencia de compresión media del orden de los $230 \mathrm{~kg} / \mathrm{cm}^{2}$, mientras que el de la cantera es de unos $800 \mathrm{~kg} / \mathrm{cm}^{2}$, también se obtienen diferencias apreciables en las densidades.

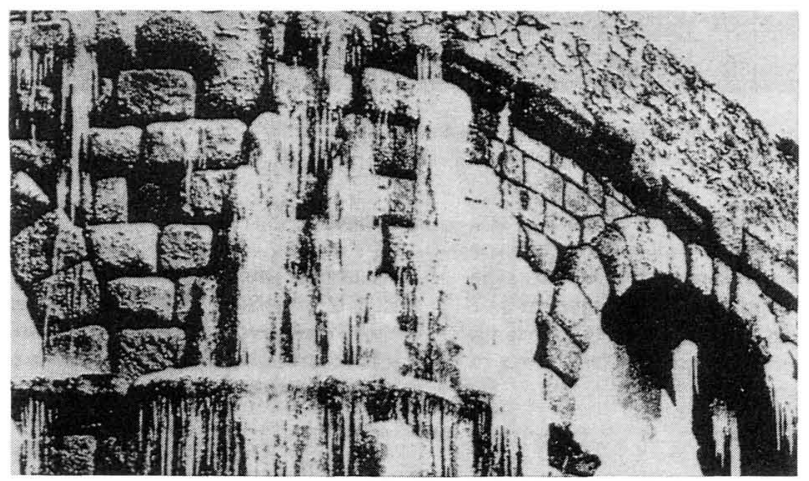

Una idea de hasta qué punto el hielo puede abrir las fisuras en la piedra e incluso separar unos sillares de otros, nos la puede dar esta conocida fotografia de los carámbanos producidos por fugas en la conducción superior, en el codo donde cambia más bruscamente de dirección el Acueducto. (fotografía extraída del libro de Aurelio Ramírez Gallardo "Supervivencia de una obra hidráulica").

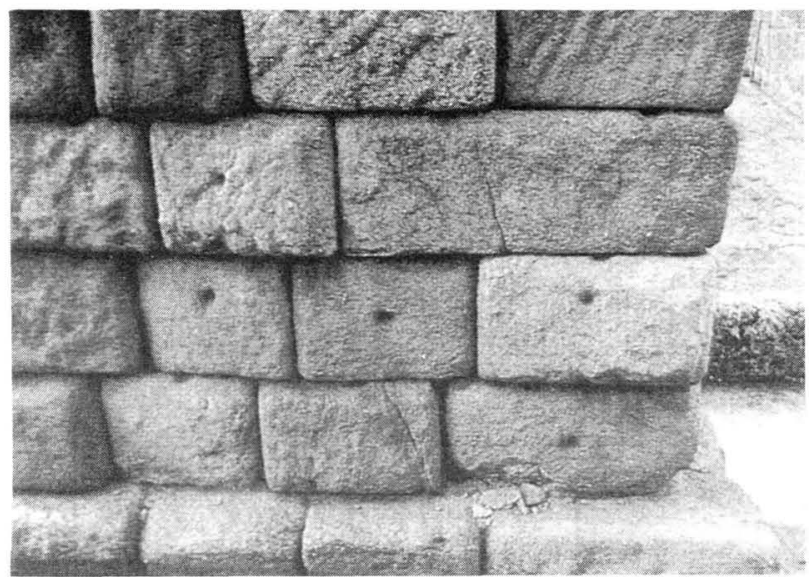

Pila con sillares aparentemente sanos en su textura superficial (aún conservan el tratamiento original de sus caras mediante escafilado y las hendiduras para que la gafa o tenazas metálicas usadas en el izado de las piedras pudiera agarrar el sillar). Sin embargo aparecen fisuras y desmoronamientos importantes. (fotografía original de $19 \times 12,5 \mathrm{~cm}$ del propio autor)
En los análisis de envejecimiento acelerado se observa que, lo que más ataca al granito es el ambiente ácido, es decir, el ácido sulfúrico, después los ciclos de hielo y deshielo, $y$, por último, en un nivel casi insignificante, el calentamientoenfriamiento y la humedad-sequedad; por lo tanto nos encontramos, en el caso del Acueducto, con un granito altamente sensible a la contaminación. En las muestras de cantera es prácticamente imposible producir ningún deterioro con ensayos similares de envejecimiento.

Una de las cuestiones de mayor interés, de cara a examinar el estado del granito en cualquier momento de un modo no lesivo, ha sido el determinar una correlación entre la velocidad de transmisión de ultrasonidos y la densidad y resistencia de la piedra. Para ello se han efectuado mediciones en 400 sillares, de modo que ahora se tiene calibrado el "termómetro" que nos da el estado de degradación del sillar en concreto, simplemente poniendo en contacto con la piedra dos palpadores.

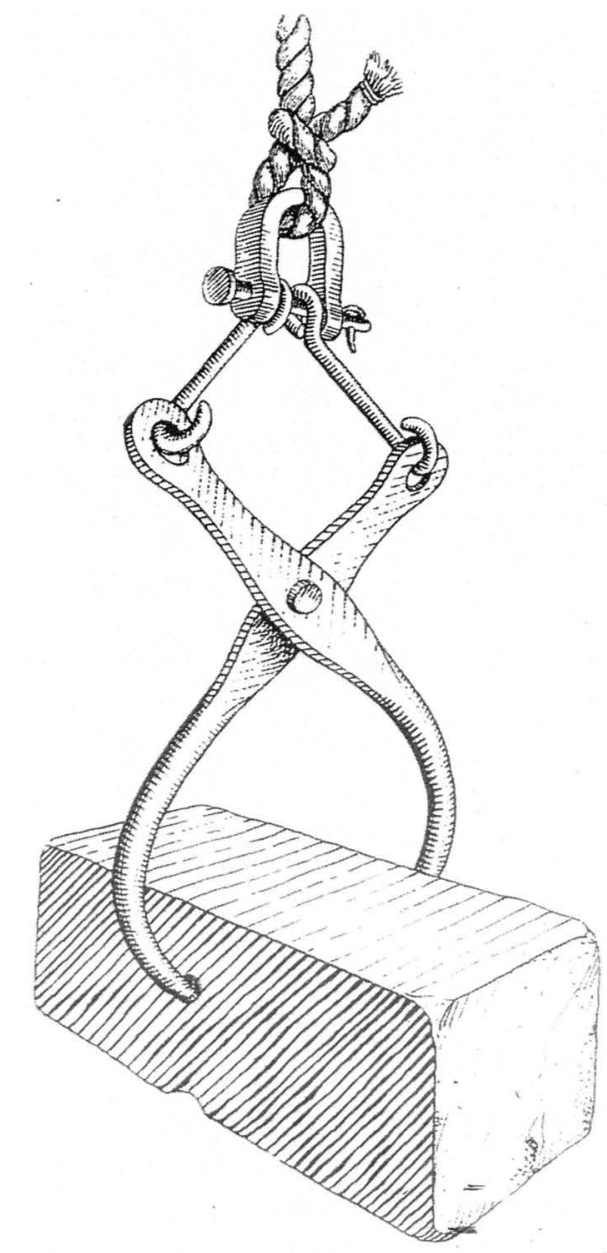

Dibujo de la supuesta tenaza metálica para izar sillares. 


\section{Endoscopias}

Un tema que parecía fundamental estudiar era el estado de las juntas entre los sillares, inclusoel cómoestaba construido el Acueducto por el interior, qué había en el interior de las pilas, sobre todo en la zona inferior de las pilas de mayor altura (y mayor sección).

En unprincipio hicimos nuestra propia hipótesis geométrica de distribución interior de sillares y al tomar algunos testigos se comprobó que, efectivamente, el interior era también de sillares de granito, con un despiece parecido al que habíamos supuesto.

A pesar de todo, para la observación de los sillares y de las juntas en el interior de las pilas, se introdujeron endoscopios con una cámara de video asociada, que permite almacenar la secuencia de las imágenes obtenidas.

Se puede observar que el interior está incluso más deteriorado que el exterior, precisamente debido a que las caras de los sillares no están sometidas a lavado y, por lo tanto, tienen una superficie más rugosa.

Al mismo tiempo es previsible que haya más nivel de microorganismos, puesto que los rayos ultravioletas no inciden directamente en las mismas. Por otro lado, el tamaño de las juntas, muy abiertas en algunos casos, permite que dentro haya nidos de aves, trozos de madera, cañas, elementos vegetales, etc., y el material de arrastre del agua y del aire.

Se puede concluir afirmando que existe una degradación en el interior, al menos similar, a la que hay por el exterior. Es interesante observar esta degradación, puesto que el nivel de contacto entre un sillar y otro no es el que originalmente fue previsto sino que, debido a pérdidas de volumen, los contactos entre los sillares se realizan de forma puntual y, en algunos casos, este material de arrastre está funcionando como si fuera aglomerante entre un sillar y otro, sirviendo como almohadilla.

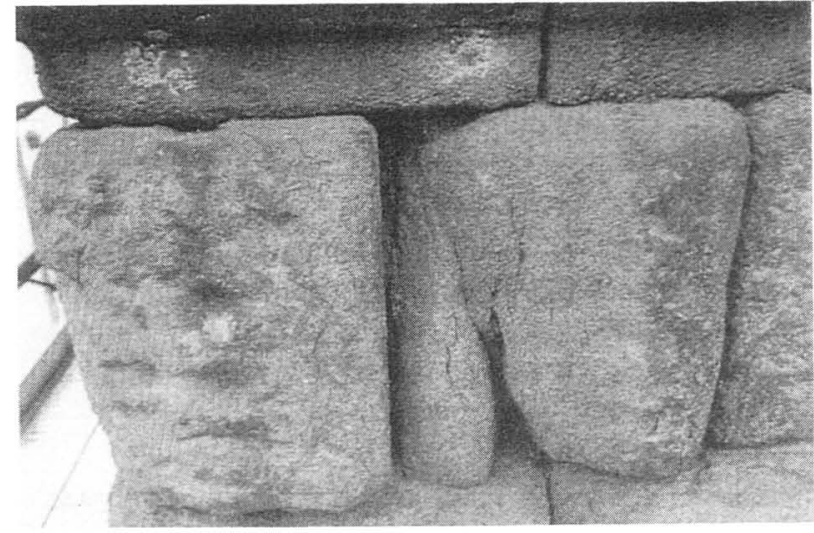

En muchos casos, una grietaque se hainiciado justo sobre una junta entre sillares inferiores, acaba dividiendo el sillar en dos partes muy meteorizadas. (Fotografía original de $19 \times 12,5 \mathrm{~cm}$ del propio autor).

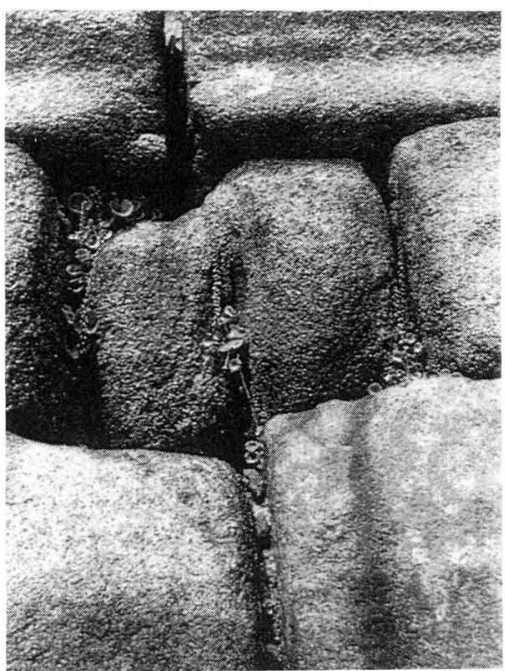

Los elementos vegetales también juegan su papel en el deterioro arraigando en el material deleznado depositado en las juntas. (Fotografía original de $19 \times 12,5 \mathrm{~cm}$ del propio autor).

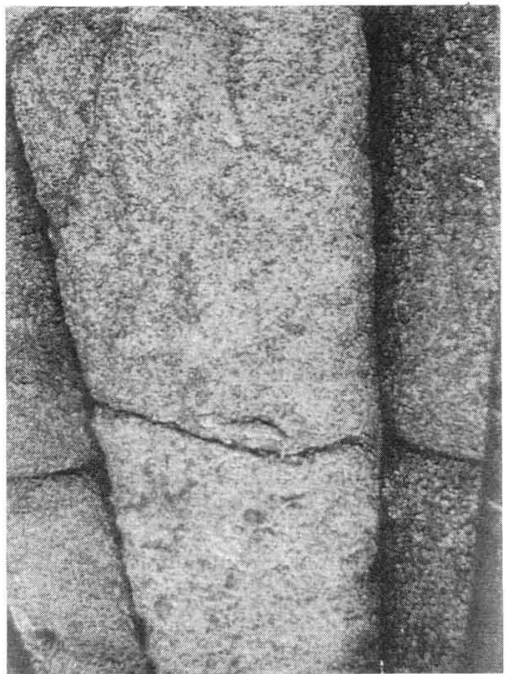

Un sillar pasante en las dovelas de la arcada superior que está ya totalmente dividido en dos partes. Ejercía una función de atado entre las dos hojas de sillares que forman los arcos superiores, que ahora tenderán a abrirse cada vez más. (Fotografía original de $19 \times 12,5 \mathrm{~cm}$ del propio autor).

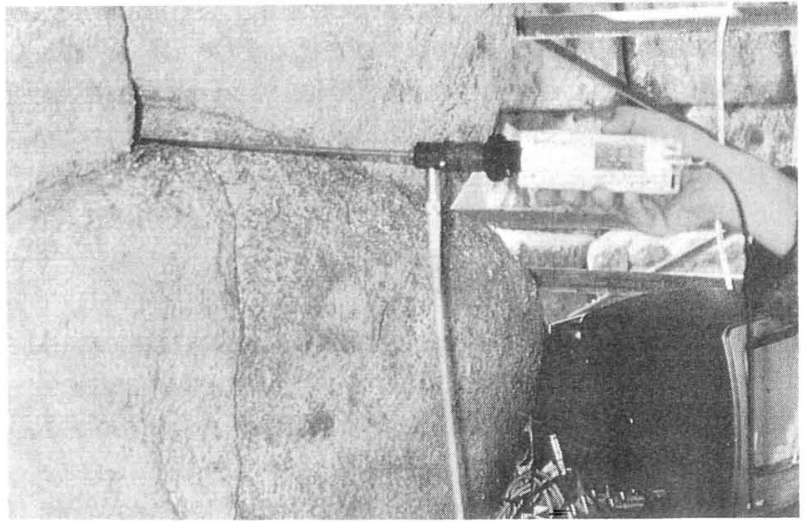

Endoscopio utilizado para inspeccionar el interior de las pilas entre los sillares. (Fotografía cedida por GEOCISA). 


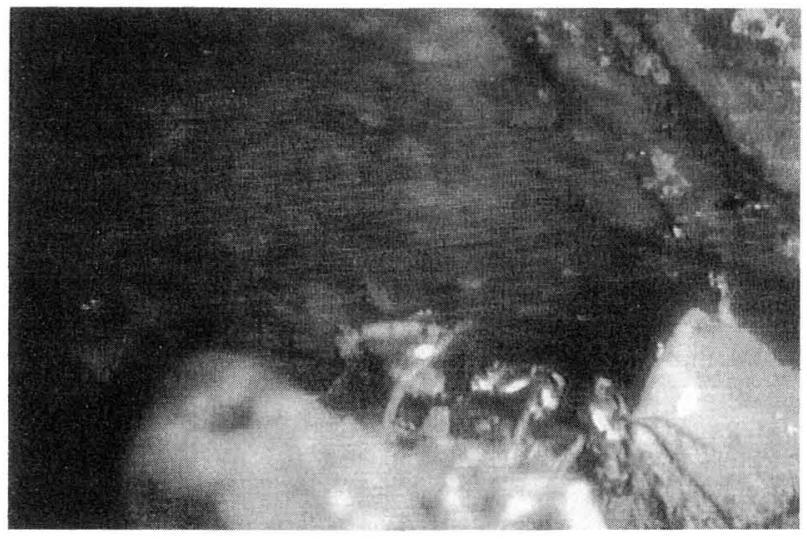

Imagen de video a través del endoscopio, donde se percibe una hormiga en la junta entre sillares. (Fotografia cedida por GEOCISA).

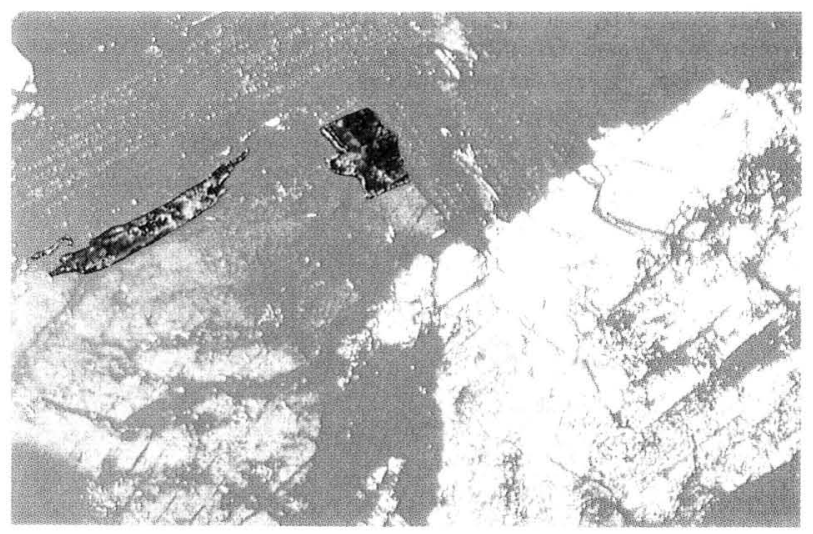

Microfotografia de granito extraido del Acueducto. Se observa cristal de plagioclasa alterado y fisurado, feldespato potásico con menor grado de alteración: biotita y moscovita. (Fotografía extraída del estudio de lapiedra efectuado por GEOCISA).

Estudios sobre la estructura del Acueducto

E1 estudio sobre el comportamiento estructural del Acueducto se está llevando a cabo mediante tres métodos; uno, un análisis vectorial mediante equilibrio que se ha realizadoa partir de un programa de ordenador, desarrollado ex profeso por nuestra propia oficina, otro de ellos es utilizando modelos de elementos finitos $\mathrm{y}$, un posible tercer camino, es utilizar un procedimiento que maneja bloques con rozamientos, similar a lo que puede ser en este caso el Acueducto, sillares en contacto sin ningún material entre sí y sometidos a rozamiento.

Mediante análisis vectorial con ordenador se ha comprobado el comportamiento del Acueducto, primero a peso propio, observándose que tiene un diseño bastante proporcionado de la sección de las pilas respecto al peso que tiene arriba, de modo que las tensiones a las que se ve sometido, prácticamente son constantes en las mismas, y del orden de $6 \mathrm{~kg} / \mathrm{cm}^{2}$. Respecto a la acción transversal eólica, no se producen, prácticamente desvíos importantes de las resultantes de tensiones interiores, de modo que prácticamente las tensiones aumentan del orden de un $20 \%$, quedándose en unos $7 \mathrm{~kg} / \mathrm{cm}^{2}$ (siempre estamos hablando de tensiones medias globales).

Hemos utilizado también este modelo para hacer simulaciones de roturas y ver qué material se vería involucrado en una posible rotura local. Para ello se han supuesto roturas en pilas y dovelas, en el caso de supuesta rotura local en una pila, simplemente se producen concentraciones de tensiones que multiplican el valor medio inicial por 3 , sin que nos acerquemos, en principio, a los valores medios de rotura a compresión medidos en los ensayos.

Para el caso de rotura de dovelas, la rotura local de una dovela de la arcada inferior no implicaría tampoco ninguna caída en cadena de otras pilas contiguas, puesto que el peso que hay en esa zona ya es suficiente como para estabilizar la diferencia de empuje que se produciría entre el arco que existe y el que se ha partido.

No podemos decir lo mismo de las dovelas superiores, puesto que si no existiese el canal superior como elemento que funcionaría transmitiendo la compresión del arco, una rotura en una dovela superior supondría roturas de pilas contiguas, de modo que podría producirse, en ese caso, un efecto de castillo de naipes.

Se ha aprovechado también el modelo en ordenador para comprobar el efecto de la introducción de una posible carga puntual en el canal, ante la posibilidad de colocar, por ejemplo, una "barquilla" de mantenimientoque discurriera por la zona superior del acueducto. Se ha comprobado que la carga puntual máxima que resiste la arcada superior es alrededor de 2,75 toneladas.

Finalmente, utilizando siempre el mismo modelode análisis vectorial, se ha comprobado cuál es la carga máxima admisible puntual en la arcada inferior, el estado de todas las pilas asimétricas, la introducción de unos cosidos "activos", etc., en definitiva, todas aquellas situaciones susceptibles de intervenciones o posibles estados posteriores.

Hemos estudiado también un modelo en tres dimensiones del tímpano inferior, utilizando un programa standard de elementos finitos (el "SAP90"), simplemente para detectar cuál sería el punto de tensiones más desfavorables donde aparecerían las roturas (tensión combinada según criterio de Von Misses), y se comprueba que es precisamente, justo encima del salmer, en el eje central de simetría.

Disminuyendo aún más la escala del análisis, hemos procedido también a estudiar un modelo con elementos tridimensionales (también mediante el "SAP 90") que simula un sillar con una junta sobre él y con apoyos no 
continuos en su base, debido al hueco producido por una pérdida de volumen en la junta y por diferencia en el plano de apoyo entre dos sillares contiguos. Las conclusiones en este caso hay que entenderlas siempre comovalores relativos o indicativos de los que pudiera ocurrir. Los resultados nos indican que para tensiones medias de compresión en la parte superior del orden, por ejemplo de 10, unos apoyos precarios, tal como se han simulado, pueden provocar tensiones hasta 30 veces mayores de tracción que, evidentemente, iniciarían roturas como las que se pueden apreciar en gran parte de los sillares, grietas que van de junta a junta atravesando el sillar.

El Departamento de Estructuras de la E.T.S.A.M.está colaborando en el análisis estructural mediante otros modelos de comportamiento. En primer lugar, se ha realizado un estudio del comportamiento térmico del Acueducto como un elemento global, las conclusiones son curiosas puesto que, considerando el Acueducto globalmente, o no se produce ningún tipo de deformación y simplemente aumenta la tensión de comprensión entre unos sillares y otros hasta $6 \mathrm{~kg} / \mathrm{cm}^{2}$ (no es un valor alto, pero nos indica que la dilatación térmica produce tensiones similares en cuantía a la del peso propio) o bien, si no hubiera incrementode tensión, si no hubiera acomodaciones entre unas piedras y otras, habría deformaciones transversales muy altas (hasta del orden de $1 \mathrm{~m}$ ), cosa que no se ha detectado ni se ha medido. En ese sentido, las mediciones de desplazamientos transversales y de desplazamientos relativos entre dos sillares contiguos, intentan "cazar" esta acomodación debida a los esfuerzos térmicos.

También se ha investigado en el Departamento de Estructuras con el programa ANSYS, mediante elementos finitos y teoría de fracturas, la aparición de grietas debido alas concentraciones de tensiones que se producen alrededor de las juntas entre sillares, comportamientos térmicos locales y análisis dinámico.
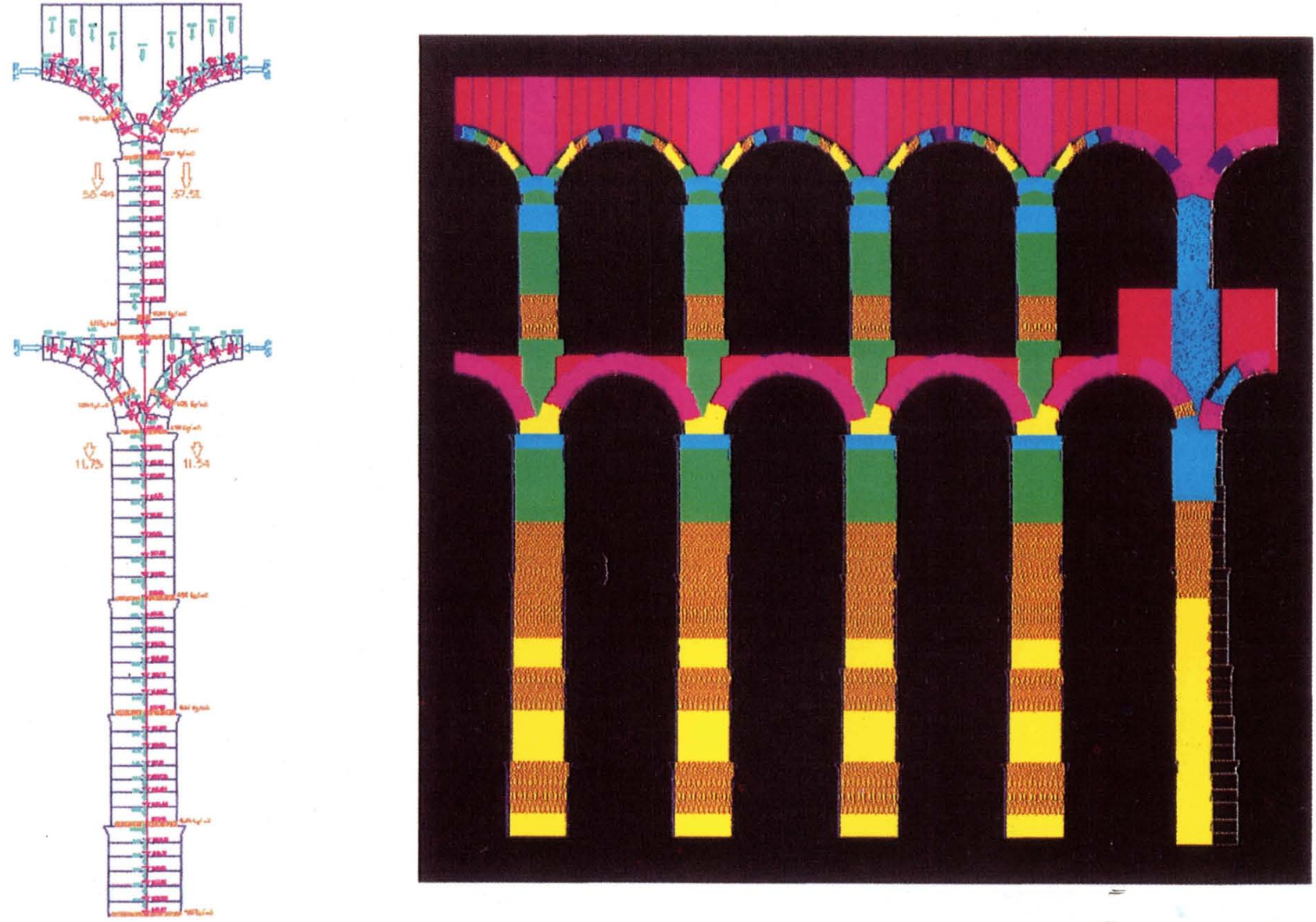

Estudio del comportamiento estructural mediante Análisis Vectorial Automático, método diseñado especialmente por nuestra oficina. (Expuesto, a partir de entonces, en múltiples simposium). 

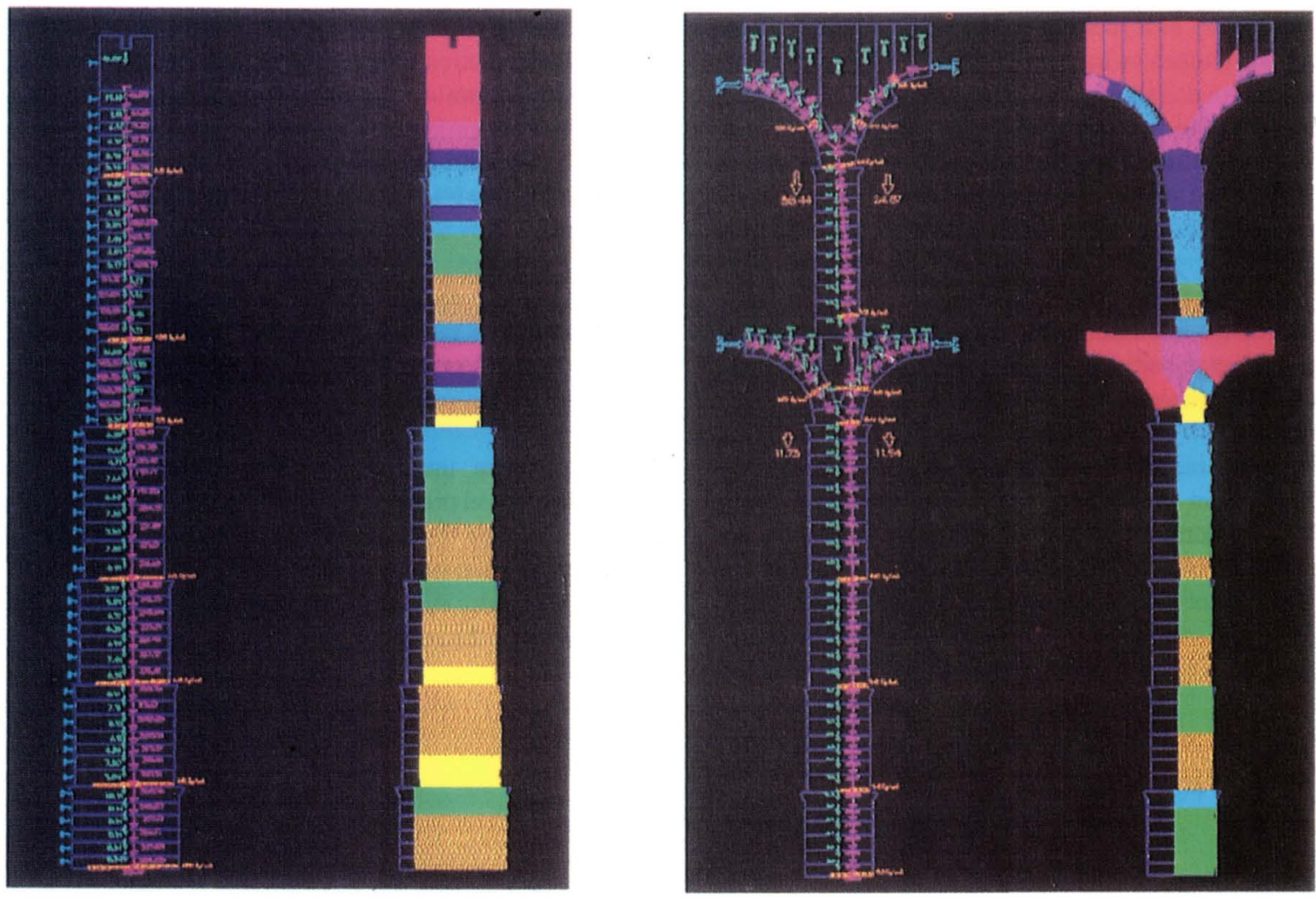

Además de analizar el comportamiento ante las acciones habituales, se ha estudiado la posible incidencia o efecto de posibles roturas parciales.
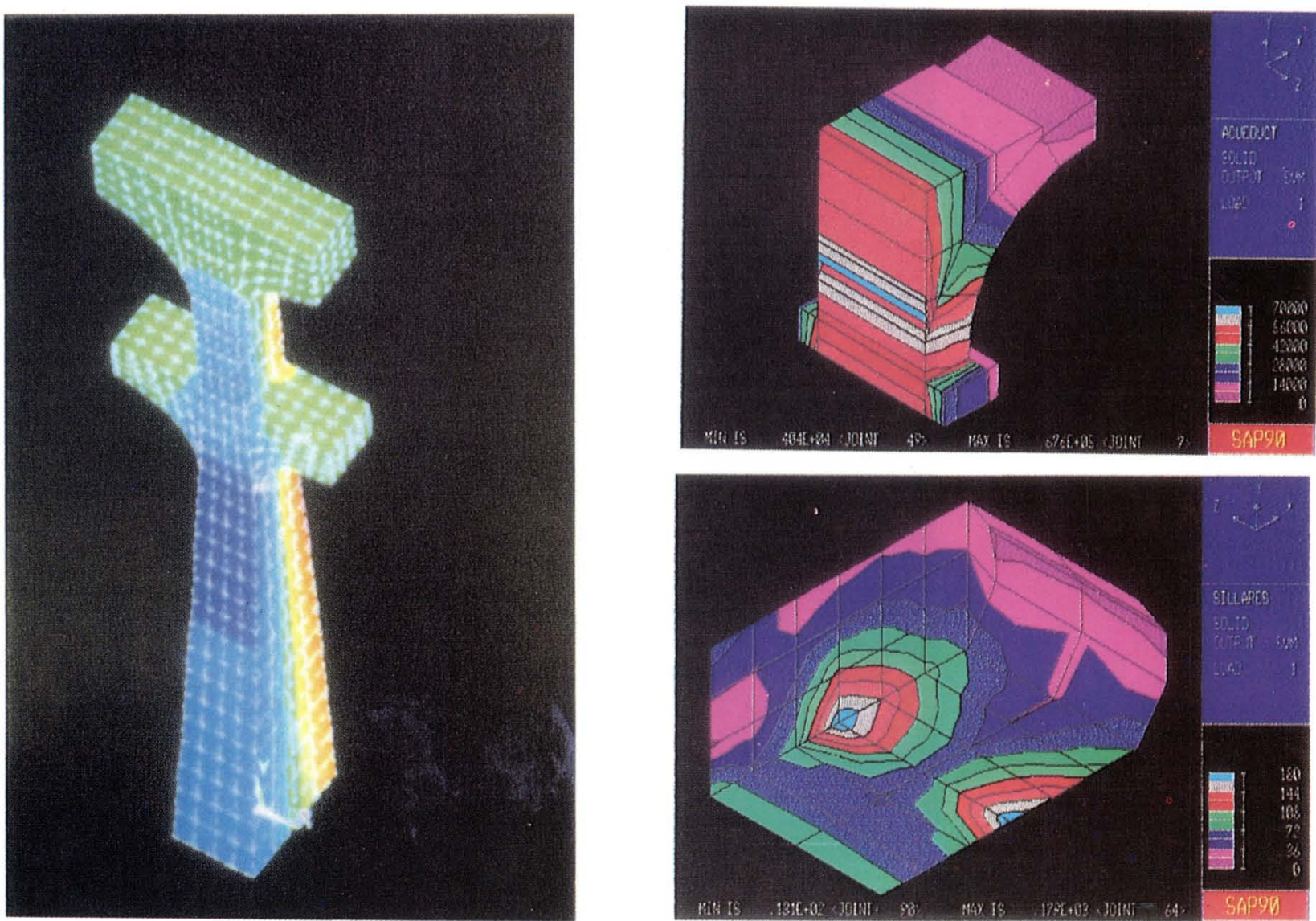

Mediante programas de Elementos Finitos se ha estudiado el comportamiento térmico, el comportamiento ante vibraciones y el proceso de formación de grietas y fracturas locales en sillares.

(c) Consejo Superior de Investigaciones Científicas Licencia Creative Commons 3.0 España (by-nc) 


\section{Medición de movimientos}

Aprovechando los puntos de control de movimientos implantados en julio de 1986 , dentro de los trabajos que también realizó la empresa GEOCISA, se han realizado mediciones con la misma metodología en septiembre de 1992 y marzo de 1993.

En diciembre de 1993, se han realizado diversas mediciones a lo largo de todo un día para tener diferentes temperaturas. Mediciones tanto globales (en una longitud de $30 \mathrm{~m}$ del acueducto) como locales (en $40 \mathrm{~cm}$, es decir, movimientos relativos entre sillares colindantes).

Realmente había que buscar una época en la que existiese un temperatura fría y un soleamiento importante y realizar distintas mediciones para intentar captar algún tipo de movimiento que nos indique la dilatación térmica como tal o la reacomodación entre sillares.

A la espera de resultados definitivos, parece ser que se han detectado movimientos de ajuste entre sillares ante las variaciones térmicas. Esto sería lo único que justificaría las afirmaciones del tipo de que "el Acueducto es una estructura articulada" y que el hacerla monolítica puede alterar sensiblemente' su comportamiento estructural.

A efectos de peso propio y de viento esto no tiene ningún sentido, puesto que las tensiones son mínimas, y precisamente el monolitismo favorece la transmisión uniforme de las mismas. Sin embargo, no ocurre lo mismo si a nivel de dilataciones térmicas sí puede existir reacodación entre unos sillares y otros, ya que esta cuestión disipa movimientos y reduce tensiones de acodalamiento.

\section{Medición de vibraciones}

Se ha vuelto a medir transmisión de vibraciones a pie del Acueducto

Ya se hicieron medidas de este tipo en el año 1986 pero, en este caso, se han querido medir en varias direcciones y dirigidas a la utilización como "input" en un análisis dinámico posterior.

Por un lado, se hace saltar a un camión desde una determinada altura (la de un tablón) junto al Acueducto, prueba que se utiliza normalmente en puentes, de modo que se puede comprobar con unos acelerómetros la transmisión de la vibración al Acueducto que produciría un tráfico rodado cercano.

Por otro lado, para poder medir el efecto de obras cercanas, se comprobó la transmisión de las vibraciones de un martillo neumático, golpeando el suelo cerca del Acueducto.
El resultado de estas mediciones es que apenas son perceptibles las vibraciones en el Acueducto, puesto que había que amplificar tanto la señal que prácticamente se captaban sólo ruidos.

\section{Intervención en pilas 67,68 y 69}

Como continuación de los estudios que se estaban realizando, la Junta de Castilla-León estimó oportuno intervenir en las pilas 67,68 y 69 para completar los conocimientos que se tenían sobre la diagnosis del Acueducto y para tener experiencias concretas de restauración en los propios sillares.

Se ha determinado, en primer lugar, para todos y cada uno de los sillares, la velocidad de transmisión de ultrasonidos, medida totalmente objetiva y comparable en el futuro del estado de cada una de las piedras.

Se han probado distintos procedimientos de limpieza según las distintas capas y costras de suciedad existentes: sulfatos, depósitos de polvo y contaminación, pintadas, etc., estudiando la efectividad, el rendimiento y la agresión de cada uno.

Se han estudiado los procedimientos para bulonar sillares partidos, para microcoser grietas y para sellar fisuras.

Se han estudiado distintos tipos de granito artificial para efectuar reparaciones locales y se han efectuado pruebas de enfundados en sillares con gran pérdida de sección.

Se han probado distintos procedimientos de consolidación superficial y mediante inyecciones, así como también procedimientos de hidrofugación, con la intención de ver su comportamiento futuro.

Se ha estudiadoel tratamiento a efectuar en lazona superior del canal y de la mampostería exterior.

Todo esto ha sido complementado con diversos ensayos en laboratorio, de modo que han quedado claros los procedimientos iniciales de intervención en los sillares del Acueducto.

\section{Intervenciones realizadas en pilas 102 a 110}

Se trata de eliminar cualquier posible peligro de desprendimiento o caída de trozos de granito, así como ralentizar el proceso de degradación de los sillares, acometiendo sólo aquellas labores imprescindibles para garantizar la unión y consolidación de sillares con zonas partidas, evitando en todo lo posible acciones no necesarias que impliquen irreversibilidad. Se reatizan las siguientes operaciones: 


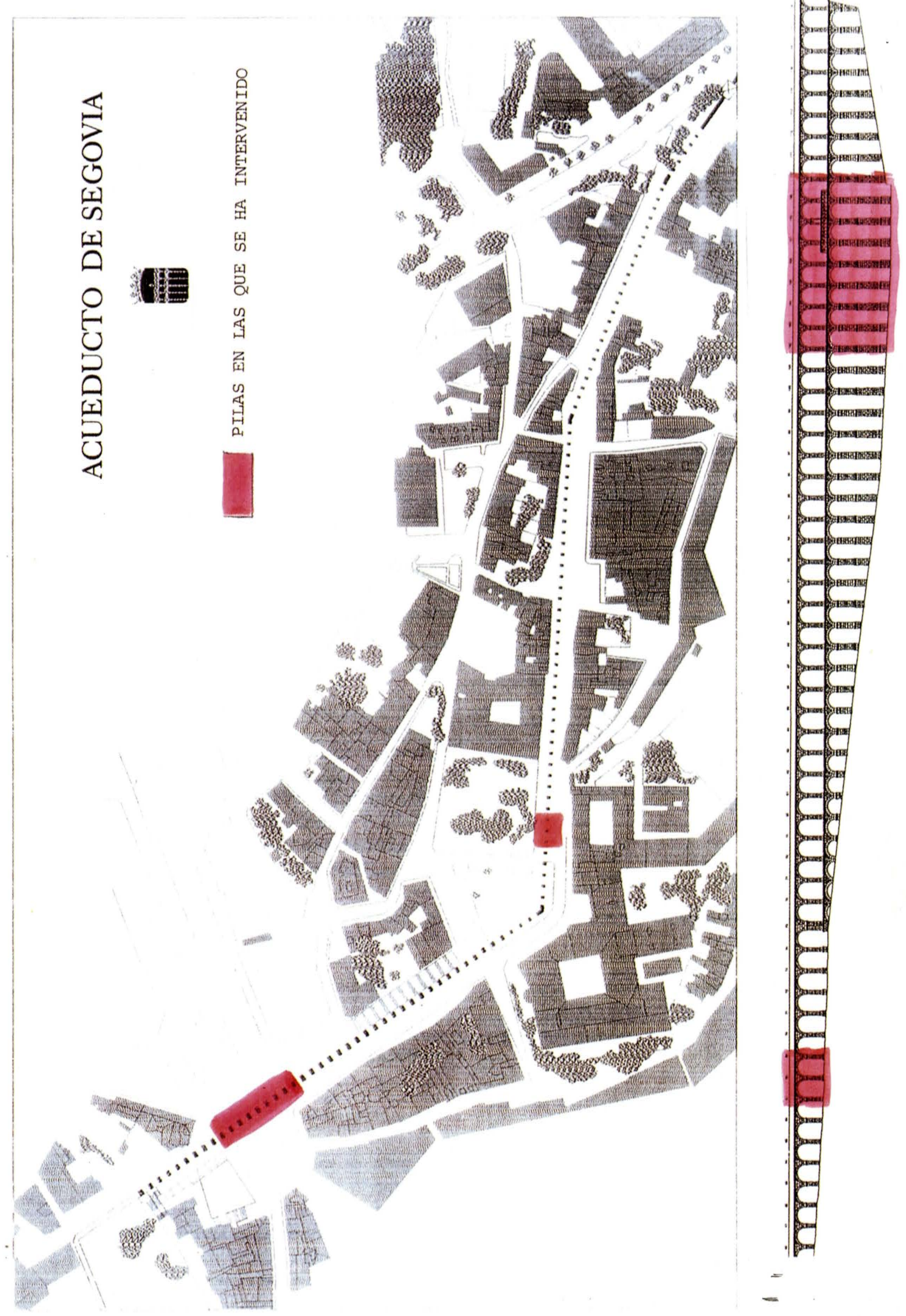


- medición de la velocidad de transmisión ultrasónica en todos los sillares, lo cual sirve para discriminar los sillares con más deterioro y para tener una lectura "cero" anotada para cada sillar;

- arrastre manual y extracción del material suelto entre las juntas de los sillares, para eliminar el medio ácido agresivo que implica la mezcla con material orgánico;

- limpieza no abrasiva controlada de toda la superficie exterior, mediante el procedimiento "micro-pulling" (cepillado con microproyección de sílice y aspiración simultánea) y lavado posterior con agua alcoholada (biocida), para regularizar el aspecto externo y ralentizar deterioros posteriores debidos a micro-organismos y depósitos de suciedad;

- sellado de fisuras mediante inyección de resina epoxídica pura (de formulación idéntica a la utilizada en 1973, cuyo buen comportamiento ha sido comprobado), de modo que se evita la progresión haciauna rotura posterior, ya que el agua que entra actúa como una cuña al helarse;

- microcosido de piezas partidas, para devolver la unidad a cada sillar, mediante perforaciones de $10 \mathrm{~mm}$ de diámetro de longitudes entre 10 y $30 \mathrm{~cm}$ por término medio, introducción de redondos roscados de acero inoxidable de $5 \mathrm{~mm}$ de diámetro e inyección de resina epoxídica;

- bulonado de "sillares-llave" partidos, mediante perforación pasante de $150 \mathrm{~cm}$ de longitud y $40 \mathrm{~mm}$ de diámetro, introducción de bulón de fibra de vidrio e inyección de resina epoxídica;

- mejora o regularización de junta entre las dovelas que presenten una situación más crítica, de menor contacto, mediante fabricación in situ de una laja de resina no adherida a ningún sillar (utilizando parafinas como película desencofrante);

- fijación de lajas superficiales en sillares meteorizados siempre que sea posible;

- consolidación de aquellos sillares que están totalmente arenizados mediante inyecciones de resina epoxídica en masa hasta su salida superficial;

- enfundado o completación de volumen (mediante piedra artificial fabricada in situ y conectada al sillar original) en algún sillar que haya perdido gran porcentaje de sus dimensiones originales y sea vital para la estabilidad del arco o pila;

- eliminación de cánulas de inyección y restos de resinas, que previamente han sido impregnadas superficialmente de granito molido para igualar el aspecto externo;

- repaso de la mampostería que rodea la canal, para evitar caídas posteriores de ripios y limpieza del interior de la canal, descubriendo posibles salidas o derivaciones en piezas de piedra;

El posterior seguimiento en el futuro de la evolución del deterioro de todos los sillares (mediante nuevas mediciones de la velocidad de transmisión de ultrasonidos) será el que. nos habrá de indicar, en cada caso, la oportunidad de realizar nuevas intervenciones.

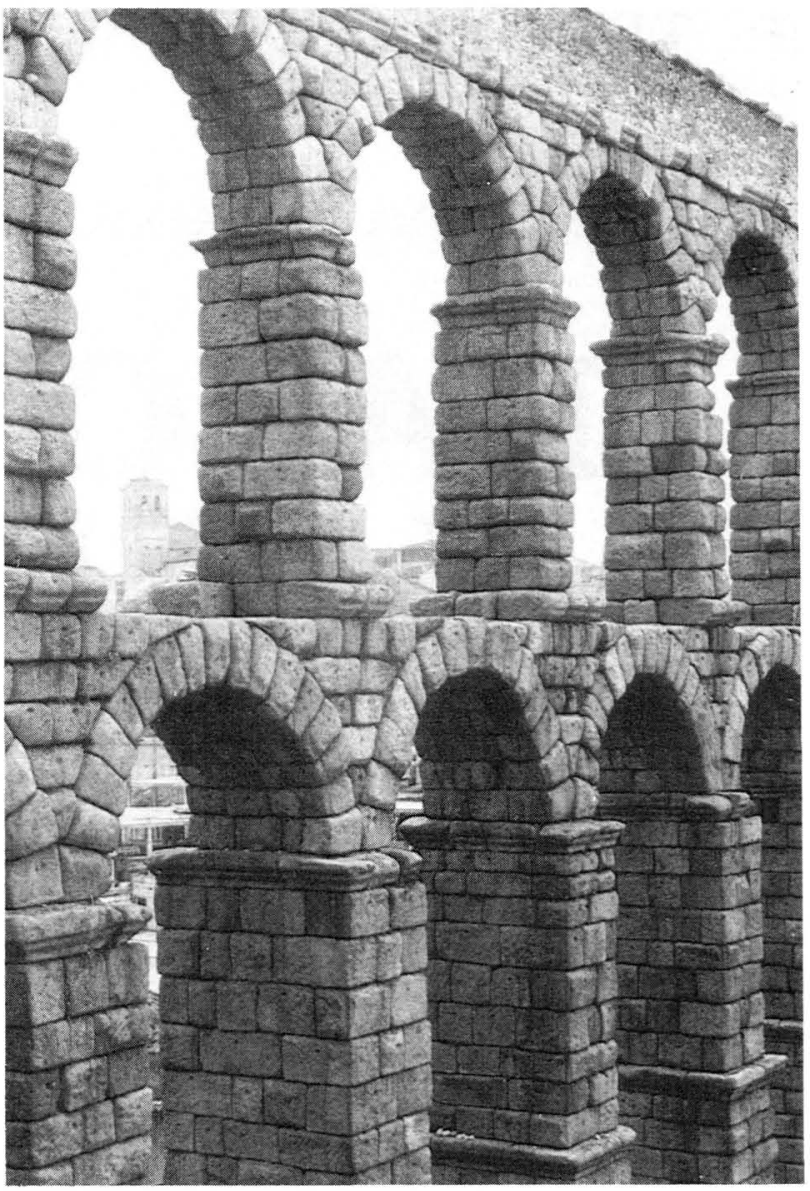

Pilas 115, 114 y 113, donde aún no se ha intervenido. (Es necesario completar la primera intervención urgente en toda la zona monumental del Acueducto, enlo concerniente a limpieza, cosidos y consolidaciones). 